\title{
Satellite-based midlatitude cyclone statistics over the Southern Ocean: 1. Scatterometer-derived pressure fields and storm tracking
}

\author{
Jérôme Patoux, ${ }^{1}$ Xiaojun Yuan, ${ }^{2}$ and Cuihua $\mathrm{Li}^{2}$ \\ Received 29 July 2008; revised 24 November 2008; accepted 15 December 2008; published 19 February 2009.
}

[1] A wavelet-based method is described for incorporating swaths of surface pressure derived from scatterometer measurements into surface pressure analyses obtained from the European Centre for Medium-range Weather Forecasts (ECMWF). The resulting modified pressure fields are used to identify low-pressure centers over the Southern Ocean and to build statistics of midlatitude cyclones during 7 years of the SeaWinds-on-QuikSCAT operational period (July 1999 to June 2006). The impact of the scatterometer-derived pressure swaths is assessed with a statistical analysis of cyclone characteristics (central pressure, radius, depth) performed in parallel on the ECMWF and on the modified pressure fields. More low-pressure centers (5-10\% depending on the season) are identified with the modified pressure fields, in particular incipient lows captured earlier than ECMWF and more short-lived mesoscale cyclones (with a life span less than 4 days). The cyclones identified with the modified pressure fields are characterized by lower central pressure and tighter isobars on average. A parallel spectral analysis reveals $\sim 1 \%$ additional energy at scales less than $2000 \mathrm{~km}$ in the modified pressure fields.

Citation: Patoux, J., X. Yuan, and C. Li (2009), Satellite-based midlatitude cyclone statistics over the Southern Ocean: 1. Scatterometer-derived pressure fields and storm tracking, J. Geophys. Res., 114, D04105, doi:10.1029/2008JD010873.

\section{Introduction}

[2] Extratropical cyclones are a critical element of the global climate. They are responsible for a large portion of the poleward atmospheric transport of heat and moisture. Moreover, cyclones play an important role in the atmospheric angular momentum budget. They are also responsible for maintaining the westerlies against surface friction [Peixoto and Oort, 1992]. Since satellite observations became available in the 1970s, many studies have focused on revealing the temporal and spatial distribution of cyclone activity and understanding cyclogenesis over the Southern Ocean [Carleton, 1983; Carleton and Carpenter, 1989, 1990; Turner and Row, 1989; Heinemann, 1990; Fitch and Carleton, 1992; Carrasco and Bromwich, 1993; Carleton and Fitch, 1993; Sinclair, 1995, 1997; Turner and Thomas, 1994; Turner et al., 1998]. Carleton and Carpenter [1989, 1990] found that intraseasonal variations in the location of maximum polar low occurrence are consistent with the large-scale changes in the long waves associated with the semiannual oscillation [van Loon et al., 1993; Simmonds and Jones, 1998; Walland and Simmonds, 1999] of surface pressure. They also showed that the interannual variations of polar low occurrence were partially related to the wavenumber 1 pattern in the sea level pressure field and affected

\footnotetext{
${ }^{1}$ Department of Atmospheric Sciences, University of Washington, Seattle, Washington, USA.

${ }^{2}$ Lamont-Doherty Earth Observatory of Columbia University, Palisades, New York, USA.

Copyright 2009 by the American Geophysical Union. 0148-0227/09/2008JD010873
}

by the El Niño-Southern Oscillation (ENSO) events. More recently, Simmonds [2003] and White and Simmonds [2006] showed that enhanced cyclone density is collocated with negative sea-level pressure anomalies associated with largescale sea-surface temperature anomalies, suggesting that coherent large scale climate variability could affect the cyclone distribution in the Southern Ocean.

[3] In contrast to previous case studies or cyclone climatology studies based on limited data records, recent studies by Simmonds and Keay [2000a, 2000b] and Simmonds et al. [2003] provide an updated and more complete Southern Hemisphere cyclone climatology. They use a Melbourne University cyclone finding and tracking scheme [Simmonds and Murray, 1999; Simmonds et al., 1999] to calculate a series of cyclone parameters, such as cyclone density, cyclone strength, track duration and length, as well as cyclogenesis and cyclolysis. They find a maximum in cyclone density south of $60^{\circ} \mathrm{S}$ near the Antarctic coast in all seasons, although concentrated in the Indian and West Pacific oceans in autumn and winter. Many of their results are quite consistent with the satellite-based analyses of Carleton and Fitch [1993] and Turner et al. [1998]. However, their results are somewhat different from those of Sinclair [1995, 1997], who located the maximum cyclone density between $50^{\circ} \mathrm{S}$ and $60^{\circ} \mathrm{S}$ in the Atlantic and Indian ocean sectors and south of $60^{\circ} \mathrm{S}$ in the Pacific Ocean. Simmonds and Keay [2000a] also show that the average lifetime of cyclones that persist beyond 1 day is just over 3 days, while the mean track length of winter (summer) systems is $2315 \mathrm{~km}(1946 \mathrm{~km})$. They find that many cyclones are generated north of $50^{\circ} \mathrm{S}$ and propagate south toward the ice pack. Yuan et al. [1999], however, showed 
that many of the large persistent systems form near the ice edge during the winter season and spin off northward over the Antarctic Circumpolar Current. Finally, Simmonds and Keay [2000b] find that the annual and seasonal mean cyclone densities have a decreasing trend over the last 40 years, which they speculate may be a consequence of global warming.

[4] These different and sometimes conflicting results tell us that there remain uncertainties about the density, the strength, and the interseasonal and interannual variability of midlatitude cyclones over the Southern Ocean. In turn, because these midlatitude cyclones contribute a large portion of the heat transport between the tropics and the poles, uncertainties in their statistics translate into uncertainties in their contribution to the overall energy budget. Condron et al. [2006] recently showed that the number of Northeast Atlantic cyclones less than $500 \mathrm{~km}$ in size was underestimated in the 40-year ECMWF reanalysis data set as compared to cloud vortices detected in satellite imagery. In this study, we therefore seek to optimize our midlatitude cyclone statistics using scatterometer measurements (first part of the article) in order to better characterize the tracks and the associated fluxes of heat and momentum over the Southern Ocean [Yuan et al., 2009].

[5] Scatterometers have revolutionized our view of the surface wind field over the world ocean [Milliff et al., 2002; Liu, 2002]. We now better understand its interactions with oceanic fronts [O'Neill et al., 2005; Samelson et al., 2006], the air-sea interactions in the intertropical convergence zone [Chelton et al., 2001; Chelton, 2005], the effects of baroclinicity on the marine boundary layer [Foster et al., 1999], and the role of the environmental flow in the development of frontal waves [Patoux et al., 2005] among many applications. Levy and Brown [1991] and Levy [1994] demonstrated the impact of the early Seasat scatterometer on our view of the Southern Hemisphere synoptic weather. Marshall and Turner [1999] later illustrated the capabilities of the European Remote Sensing (ERS) satellite in capturing midlatitude cyclone centers and fronts over the datasparse Southern Ocean. With their $25-\mathrm{km}$ grid spacing, SeaWinds-on-QuikSCAT (QS) scatterometer measurements contain mesoscale information about the surface wind field that is absent from NWP analyses [Atlas et al., 1999; Chelton et al., 2006]. When assimilated in NWP models, QS wind vectors are often "thinned"; that is, only a fraction of the wind vectors are assimilated, or rejected if they depart too drastically from the analysis. The rejected information, however, contained in QS measurements and absent from the NWP analyses might be useful for the identification of midlatitude cyclones and for a better estimation of the associated air-sea fluxes.

[6] Recognizing the value of scatterometer winds over NWP surface winds, Chin et al. [1998] developed a scheme for forcing an ocean model with scatterometer winds. The satellite winds being measured along a swath and unequally distributed in time and space over the globe, they proposed a wavelet-based method for "blending" the scatterometer winds into NWP winds. The resulting wind field contained more kinetic energy at high wavenumbers, which translated into a larger transfer of momentum to the ocean. One might consider using similar blended wind fields to identify midlatitude cyclones and calculate the associated fluxes.
However, the atmospheric depressions corresponding to midlatitude cyclones are more easily detected and tracked using pressure fields. We therefore propose to adapt the methodology developed by Chin et al. [1998] and to "modify" surface pressure fields over the Southern Ocean using scatterometer information integrated via a planetary boundary layer model. We then endeavor to use these pressure fields to improve our statistical analysis of midlatitude cyclones and their associated fluxes. Section 2 describes the data and the scatterometer-derived pressure fields. In section 3 these pressure fields are blended with ECMWF analyses using a wavelet-based method, and the method for identifying and tracking cyclones is described. The results are presented in section 4 .

\section{Data}

\subsection{QuikSCAT Winds}

[7] The pressure fields used in this study are calculated from the L2B QS surface wind vectors distributed by the Jet Propulsion Laboratory Physical Oceanography Distributed Active Archive Center (PODAAC) after removal of the wind vector measurements contaminated by rain [Huddleston and Stiles, 2000] and/or ice. QS has yielded an almost continuous record of measurements from 19 July 1999 to the present. This study is based on almost 7 years of swath-based oceanic surface pressure fields archived from 19 July 1999 to 30 June 2006.

\subsection{ECMWF Surface Pressure Analyses}

[8] The reference pressure analyses used in this study are the ds111.1 sea-level pressure analyses obtained from the European Centre for Medium-range Weather Forecasts (ECMWF) through the University Corporation for Atmospheric Research (UCAR). These analyses are output on a Gaussian (n80) grid with a resolution of about 1.125 degrees. They are interpolated on a $0.5 \times 0.5$ degree grid for the purpose of this study. Note that QS measurements have been assimilated in the ECMWF NWP model since 22 January 2002.

\subsection{Scatterometer-Derived Pressure Fields}

[9] There exist various methods for estimating the surface pressure field from surface wind vectors [Brown and Levy, 1986; Harlan and O'Brien, 1986; Hsu et al., 1997; Hsu and Liu, 1996; Zierden et al., 2000; Hilburn et al., 2003; Patoux et al., 2003, 2008]. The satellite-based surface pressure fields used in this study and referred to, here, as the University of Washington QuikSCAT (UWQS) pressure fields, are derived from QS measurements using the method described by Brown and Levy [1986] and Patoux et al. [2003]. They are available at http://pbl.atmos.washington.edu. The pressure retrieval method has been extensively described in previous articles [e.g., Patoux et al., 2008] and is only shortly summarized here.

[10] A swath of gradient wind vectors is calculated from the QS surface wind vectors using the University of Washington Planetary Boundary Layer (UWPBL) model [Brown, 1982]. The gradient wind vectors are translated into pressure gradients using the gradient wind correction described by Patoux and Brown [2002]. A pressure field is fit to the swath of pressure gradients by least-squares 

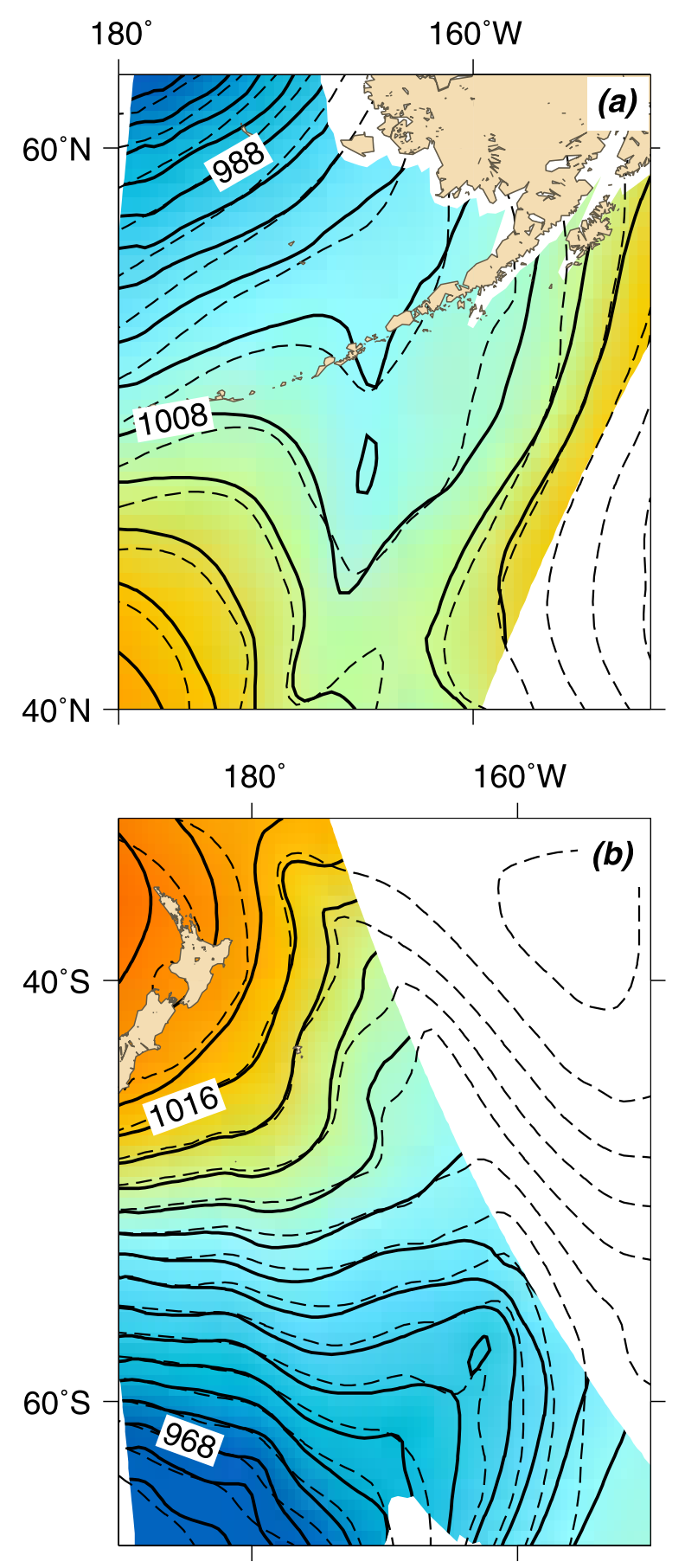

Sea-level pressure $(\mathrm{hPa})$

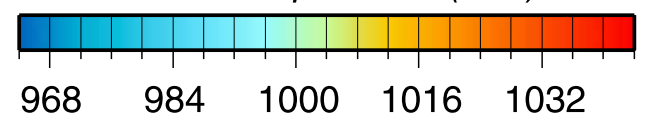

Figure 1. Mesoscale detail appearing in UWQS surface pressure fields (solid lines are 4-hPa isobars) while absent from ECMWF surface pressure analyses (dashed lines are 4-hPa isobars): (a) 3 January 2006 at 0540 UTC (QS) and 0600 UTC (ECMWF) and (b) 21 April 2005 at 1825 UTC (QS) and 1800 UTC (ECMWF). minimization [Brown and Levy, 1986; Brown and Zeng, 1994]. Patoux et al. [2008] have established that the rootmean-square difference between the UWQS surface pressure field and the closest-in-time ECMWF surface pressure analysis is on the order of $2 \mathrm{hPa}$ in the midlatitudes and $1 \mathrm{hPa}$ in the tropics. They compared the UWQS pressure fields with buoy pressure measurements and found an average correlation of 0.968 between bulk pressure gradients. Finally, a spectral analysis of the ECMWF and UWQS surface pressure fields revealed more energy at all scales in the midlatitudes in the latter product, suggesting that the UWQS surface pressure fields contain stronger pressure gradients overall than the ECMWF analyses. This is consistent with the results of Chelton and Freilich [2005], who showed a $0.4 \mathrm{~m} \mathrm{~s}^{-1}$ low bias in the ECMWF $10-\mathrm{m}$ wind speeds.

[11] The UWQS surface pressure fields might also contain more information at certain scales of motion, in particular at the mesoscale, as suggested by visual inspection of the pressure fields. Figure 1 shows two examples of UWQS surface pressure fields revealing mesoscale detail that is absent from the corresponding ECMWF analyses. Figure 1a shows a small low pressure region $\left(50^{\circ} \mathrm{N}, 165^{\circ} \mathrm{W}\right.$, south of the Aleutian Islands) embedded in the remnant of a cold front associated with a mature midlatitude cyclone further to the northwest. Figure $1 \mathrm{~b}$ shows a similar depression $\left(58^{\circ} \mathrm{S}, 162^{\circ} \mathrm{W}\right)$ along a curving cold front associated with a mature cyclone south of New Zealand. In both cases the small lows are absent from the ECMWF analysis, which shows a continuous trough. Such small-scale features can be identified with high accuracy from scatterometer-derived pressure fields. These are thus believed to contain valuable information about the position, the stage of development, and the structure of midlatitude cyclones and their attendant fronts. However, because the QS swaths unequally cover the surface of the ocean, some cyclones are only partly captured by the instrument, and the smaller depressions may fall in the gap between two successive swaths, as shown in Figure 2. Figure 2a shows two QS swaths, each intersecting one half of a mesoscale cyclone in the North Pacific Ocean, but not the center $\left(32^{\circ} \mathrm{N}, 160^{\circ} \mathrm{W}\right)$. Figure $2 \mathrm{~b}$ shows a similar case in the South Atlantic Ocean in which the center of the cyclone falls on the edge of two successive swaths $\left(42^{\circ} \mathrm{S}\right.$, $\left.18^{\circ} \mathrm{W}\right)$. These examples illustrate the limitations that one would encounter in establishing cyclone statistics from scatterometer measurements alone. Therefore, to take full advantage of the information contained in the UWQS surface pressure fields while minimizing the lack of information between the swaths, a method is sought for blending UWQS pressure retrievals into ECMWF analyses.

\section{Methodology}

\subsection{Wavelet Decomposition of Surface Pressure Fields}

[12] Wavelets are a powerful tool for the analysis of time series and geophysical fields [Foufoula-Georgiou and Kumar, 1994]. A wavelet decomposition retains the advantages of a spectral analysis, by revealing variations of the signal on different scales, while yielding information about the location of these variations in time or in space. Thus, applied to a surface wind field or a surface pressure field, a wavelet decomposition will capture and separate mesoscale 

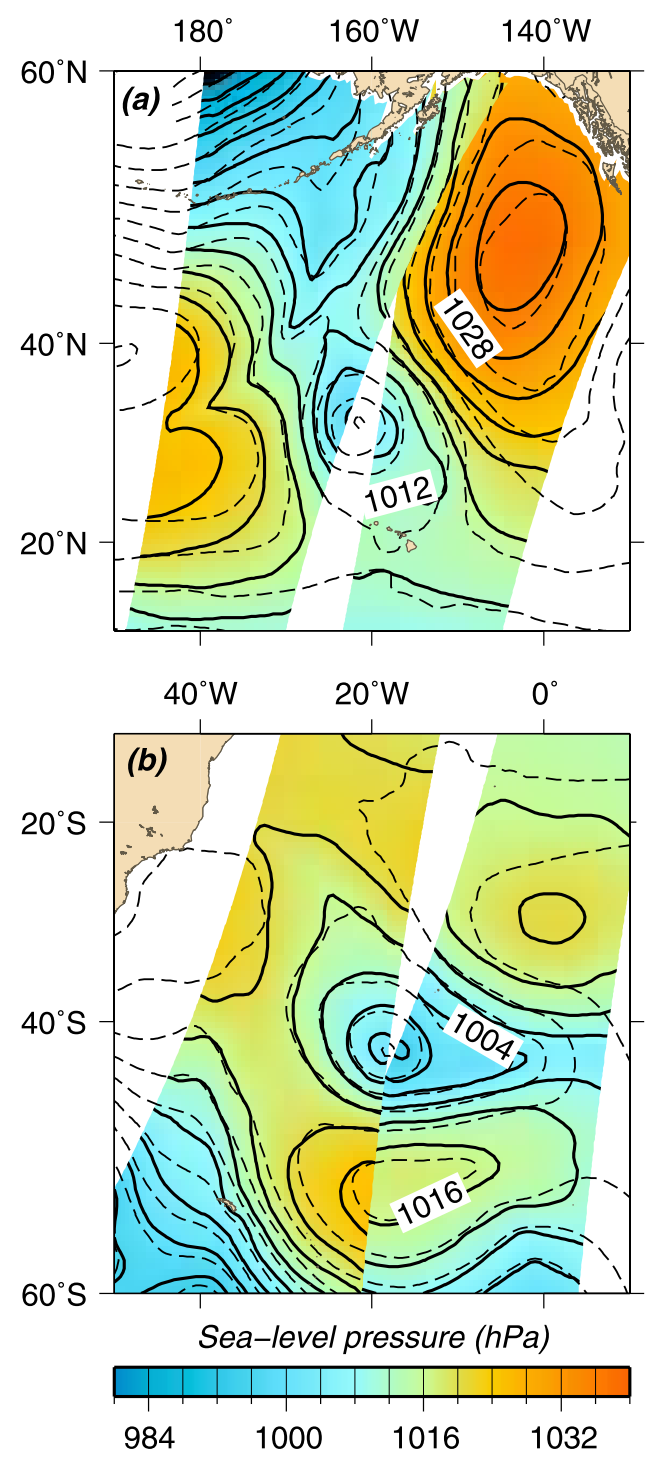

Figure 2. Examples of cyclone centers falling in the gap or on the edge of two scatterometer swaths: (a) 3 January 2005 between 0400 and 0600 UTC and (b) 23 January 2005 between 1700 and 1900 UTC. The solid lines are 4-hPa UWQS surface isobars. The dashed lines are 4-hPa ECMWF surface isobars. from synoptic-scale features while retaining information about the location of these features on the globe. Chin et al. [1998] interpolated individual swaths of scatterometer surface wind fields on a regular grid using spline functions and decomposed the resulting wind field with BattleLemarie wavelets. Their method had the advantage of operating a smooth transition across the edges of the swath. Here we use a similar approach based on the maximum overlap discrete wavelet transform (MODWT) and the least asymmetric wavelet (LA8) described by Percival and Walden [2000]. Since the QS measurements are performed on a regular grid with $25-\mathrm{km}$ grid spacing, we take advantage of the grid and perform the decomposition of the pressure field in swath coordinates. A reflection of the swath is performed in both directions to avoid edge effects [Percival and Walden, 2000]. By inverse recomposition of the wavelet coefficients up to a certain wavelet width, the detail of the pressure field is reconstructed up to a certain scale.

[13] Figure 3 shows an example of such a reconstruction of a UWQS surface pressure field on 27 January 2003, 0230 UTC south of Madagascar. Figure 3a shows the sum of the 25-, 50- and 100-km wavelet coefficients. Subsequent panels contain one more level of detail (Figure 3b: $200 \mathrm{~km}$, Figure 3c: $400 \mathrm{~km}$, and Figure 3d: $800 \mathrm{~km}$ ). Figure 3e shows the complete recomposition, i.e., the original UWQS surface pressure swath. The swath intersects a mature cyclone at $60^{\circ} \mathrm{S}$ and a secondary cyclone at $40^{\circ} \mathrm{S}$ on the cold front of the parent cyclone. As we recompose the pressure field, more information about the two cyclonic systems is being added until we capture most of their structure in Figure 3d. This last field contains all scales below (and including) $800 \mathrm{~km}$, but none of the larger synoptic-scale information.

[14] The same wavelet decomposition and detail recomposition of the ECMWF surface pressure analysis for 27 January 2003 at 0000 UTC is shown in Figure 4. A panel-to-panel comparison with Figure 3 shows that the two weather systems are present in the ECMWF analysis, but the two cyclones are less intense than in the UWQS surface pressure swath. In particular, this secondary cyclone, although present in the detail of Figure $4 \mathrm{~d}$, is too shallow to appear as a closed low in Figure 4e. The secondary depression is present in the wavelet detail, but it is overcome by the synoptic structure of the pressure

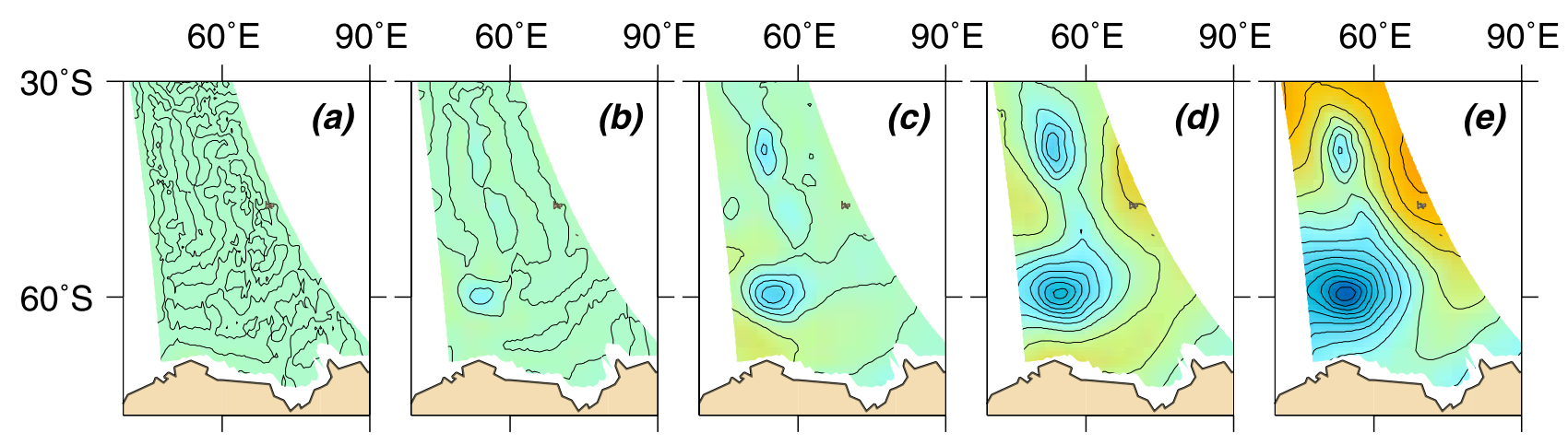

Figure 3. Wavelet reconstruction of a UWQS surface pressure swath at different levels of detail. Solid lines are 4-hPa isobars. Same color scale as in Figure 1. (a) Including 25-, 50-, and 100-km wavelet coefficients. (b) Same with 200-km coefficients added. (c) Same with 400-km coefficients added. (d) Same with 800-km coefficients added. (e) Original surface pressure swath, 27 January 2003, 0230 UTC. 


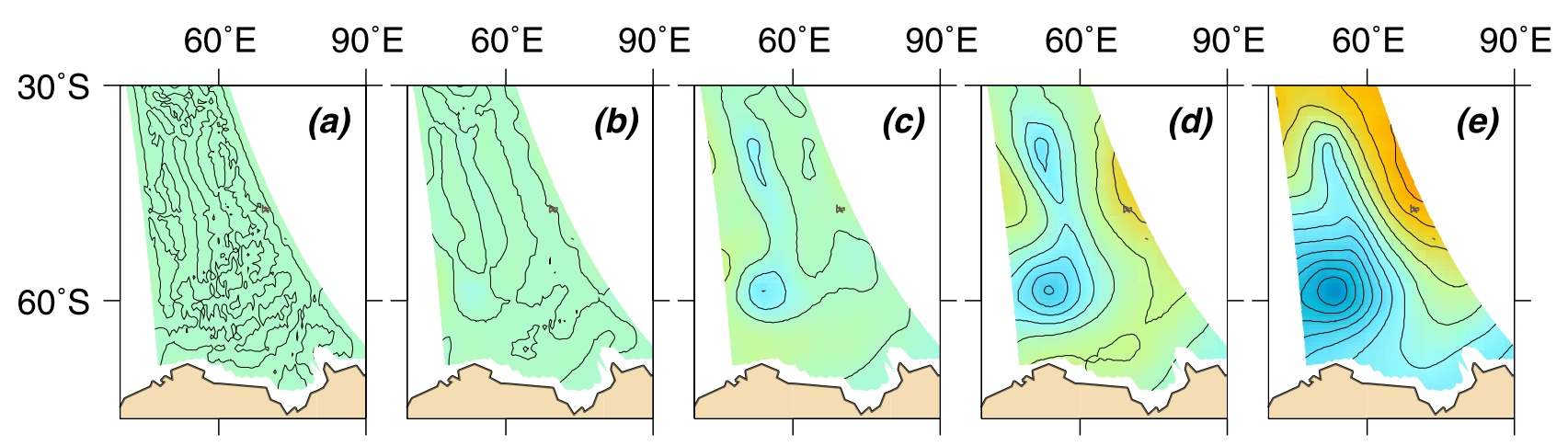

Figure 4. Same as Figure 3 for ECMWF surface pressure analysis 27 January 2003, 0000 UTC.

trough in the total recomposition. Note that the time of the satellite pass is two and a half hours after the ECMWF analysis, which could explain why the two lows are more developed in the pressure swath. However, a comparison with the 0600 UTC analysis indicates that the time lag is not sufficient to explain the difference (not shown).

[15] Following Chin et al. [1998], we substitute the ECMWF small-scale (less than and including $800 \mathrm{~km}$ ) coefficients with the UWQS coefficients and reconstruct the modified ECMWF pressure field from the new set of wavelet coefficients. This effectively "blends" the mesoscale low into the ECMWF analysis, as shown in Figure 5. The secondary cyclone now appears in the modified analysis while the synoptic-scale structure of the pressure field has been retained inside the swath, as well as the pressure pattern outside the swath. Importantly, by retaining the synoptic-scale coefficients and substituting only the mesoscale wavelet coefficients, we ensure a relatively smooth transition across the edges of the swath.

[16] Note two major limitations of this methodology.

[17] 1. There is no clear scale limit between mesoscale and synoptic scale. A mesoscale low is partly characterized by larger-scale wavelet coefficients. Moreover, features such as the mesoscale low appearing in Figure 3e sometimes fall near or under the swath edges and consequently, swath edges are sometimes detectable in the blended fields.

[18] 2. The time difference between the NWP analysis and each QS swath can be up to $3 \mathrm{~h}$, which is sufficient for dynamical features to be displaced by 100 or $200 \mathrm{~km}$ and to undergo a significant structural change. Consequently, a small spatiotemporal error is introduced into the blended product.

[19] However, even though the blending is not completely seamless, the resulting pressure fields are a first and encouraging result that provides us with a tool to assess the impact of the scatterometer measurements on the characterization of cyclones and their life cycle. Two potential impacts are investigated: (1) Are midlatitude cyclone tracks constructed from modified pressure fields different from the tracks constructed from ECMWF analyses? (2) Is there a detectable difference in the strength or depth of midlatitude cyclones depicted in the modified pressure fields as opposed to the ECMWF pressure analyses? To answer these two questions, we computed two 7-year statistics of southern hemisphere midlatitude cyclones: a first computation from ECMWF surface pressure analyses; a second computation
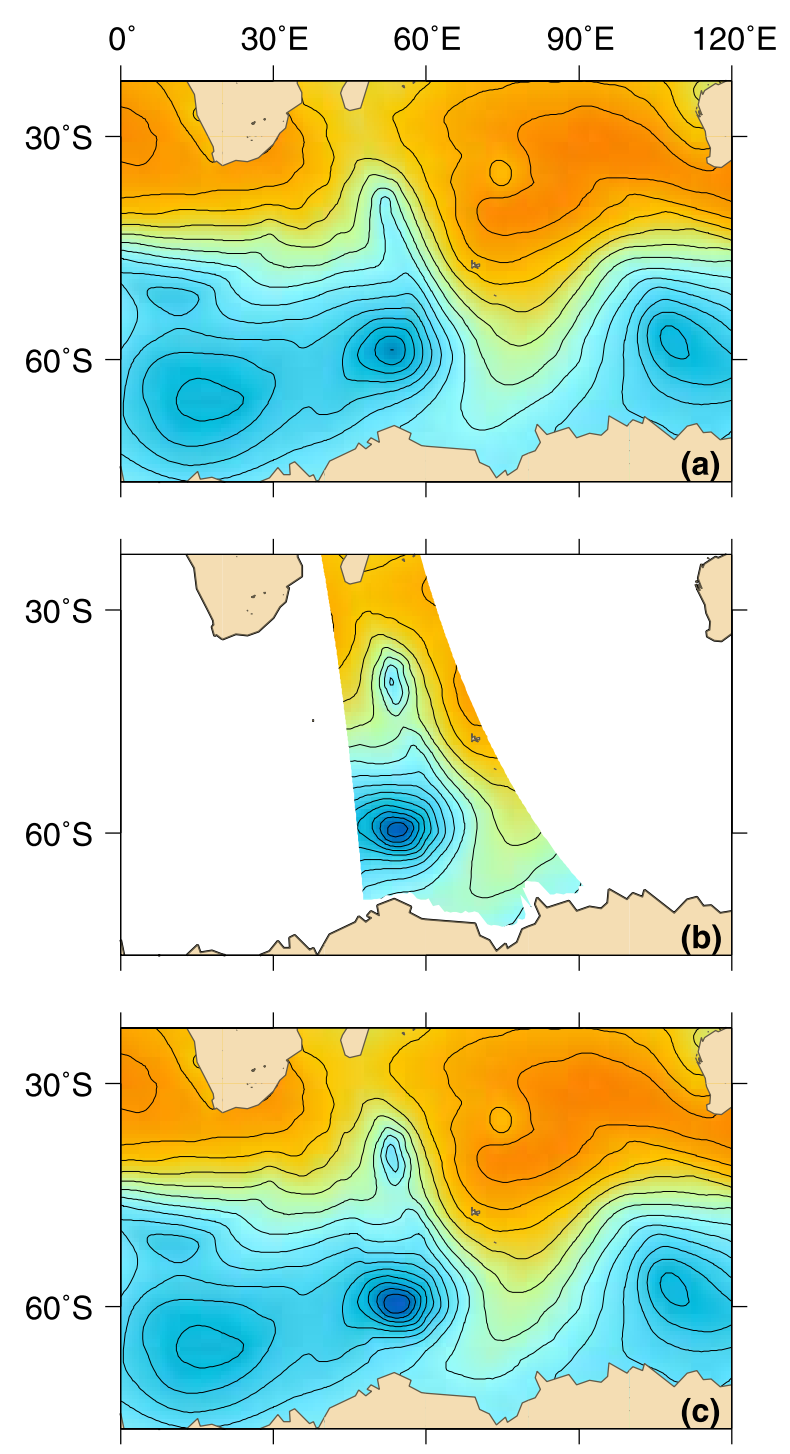

Figure 5. Blending of ECMWF and UWQS surface pressure fields by wavelet substitution and recomposition. (a) ECMWF surface pressure analysis 27 Jan 2003, 00:00 UTC. (b) UWQS surface pressure swath 27 Jan 2003, 02:30 UTC. (c) Blended surface pressure field. 


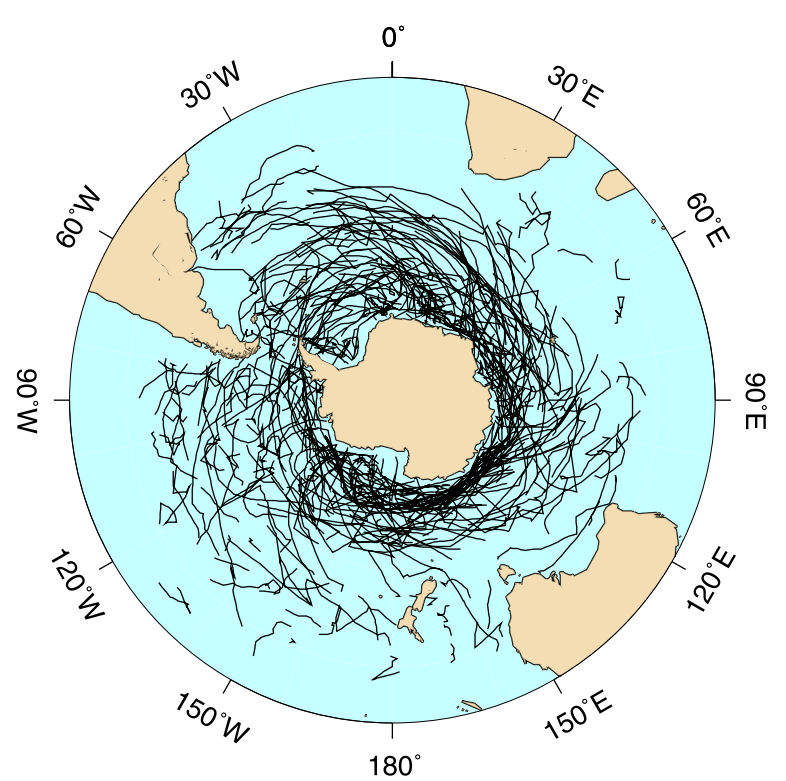

Figure 6. Tracks of Southern Hemisphere midlatitude cyclones for January through March 2003.

from the modified surface pressure fields; that is, the ECMWF analyses in which all UWQS swaths falling within \pm 3 hours of the synoptic time have been blended with the wavelet decomposition described above. This last data set will be referred to as UWPBL in the rest of this study.

[20] To compute these statistics, we need a means to identify and track midlatitude cyclones using surface pressure fields and a means to evaluate the size and strength of a cyclone, which is the subject of the next section.

\subsection{Identification and Tracking of Midlatitude Cyclones}

[21] Numerous schemes have been developed to detect the presence and estimate the strength of midlatitude cyclones from surface pressure fields [e.g., Lambert, 1988; Treut and Kalnay, 1990; Murray and Simmonds, 1991a; König et al., 1993; Hodges, 1995, 1999; Sinclair, 1997; Blender et al., 1997; Serreze et al., 1997; Hanson et al., 2004; Rudeva and Gulev, 2007]. They often rely on the detection of a local pressure or vorticity minimum and the ability to differentiate the dynamically significant cyclones from the irregularities of the pressure field using a derivative such as the pressure gradient or the wind vorticity. The method developed by Murray and Simmonds [1991a] has the advantage of detecting the presence of both "closed" and "open" lows. Grotjahn et al. [1999] use a wavelet analysis that detects both the location and the size of North Pacific cyclones. The sophisticated method of Hewson [1997] calculates the cross-front and along-front vorticity to objectively identify frontal wave cyclones.

[22] Here we use a relatively simple method in which a cyclone is selected if: (1) the grid point is over the ocean; (2) there is a true local pressure minimum (i.e., the surface pressure at the grid point is less than at the eight surrounding grid points); (3) the surface pressure at the grid point is at least $1 \mathrm{hPa}$ less than the pressure averaged over the surrounding grid points up to \pm 4 grid indices; and (4) the
Laplacian of pressure averaged over those same points is at least $0.5 \times 10^{-10} \mathrm{hPa} \mathrm{m}^{-2}$. Since the use of a true local pressure minimum precludes the identification of open lows, the total number of cyclones might be slightly underestimated. However, since our main interest is in the comparison of two data sets and the same scheme is used in both cases, we do not feel like the results are significantly impacted by the criterion. Sinclair [1997] suggests that identifying cyclones with local pressure minima tends to favor slow-moving or intense cyclones south of $60^{\circ} \mathrm{S}$, while weaker disturbances north of $60^{\circ} \mathrm{S}$ are embedded in a strong background pressure gradient and can remain undetected. He suggests vorticity maxima as a better identifier. Because our pressure fields have a 0.5 resolution, however, the vorticity field (second derivative of pressure) is quite noisy and not a good tool to detect the presence of cyclones, unless it is heavily smoothed. We therefore chose to search for pressure minima and to use the averaged surrounding Laplacian of pressure to filter out the irrelevant minima.

[23] The specific values of $1 \mathrm{hPa}$ and $0.5 \times 10^{-10} \mathrm{hPa} \mathrm{m}^{-2}$ and the number of surrounding grid points were determined subjectively by inspecting 40 hemispheric pressure fields and verifying visually that all meteorologically significant cyclones were selected without accepting too many irrelevant depressions. It is important to remember, as we pursue the analysis, that altering these values will quantitatively affect the statistics. However, our goal here is not to establish a state-of-the-art climatology, a problem that several authors have already addressed. Our main interest is in the comparison of the statistics obtained with two different products (ECMWF versus UWPBL), and the qualitative differences are relatively insensitive to slight changes in the thresholds.

[24] The statistics were established for the Southern Ocean (here defined broadly as all waters between $80^{\circ} \mathrm{S}$ and $20^{\circ} \mathrm{S}$ ) and for the period July 1999 through June 2006. For verification, a similar cyclone detection was also performed in parallel with the algorithms developed at the University of Melbourne [Murray and Simmonds, 1991a, 1991b; Simmonds et al., 1999]. Their scheme was developed for a coarser grid resolution in polar stereographic coordinates and searches for lows on a spline-fitted surface to ensure the detection of both open and closed lows. Although it is more robust than the scheme used in this study, we found our scheme better adapted to the 0.5 grid resolution of our pressure fields and better able to identify small-scale features captured by the scatterometer. Because our interpolation and identification criteria are slightly different from those of Simmonds et al. [1999], the results show some variations, but we have verified that both detection schemes yielded consistent results in a statistical sense.

[25] Cyclone tracks are reconstructed using the tracking algorithms developed by Murray and Simmonds [1991a, 1991b] and Simmonds et al. [1999]. At each synoptic period, the subsequent positions of existing cyclones are predicted and compared with the centers identified at the following synoptic time (6 hours later). A probability is calculated for each pair of positions and a matching is sought that maximizes all probabilities of association. An example of cyclone tracks reconstructed for the period January-March 2003 is shown in Figure 6 and compares 
$160^{\circ} \mathrm{E} \quad 180^{\circ} \mathrm{E}$
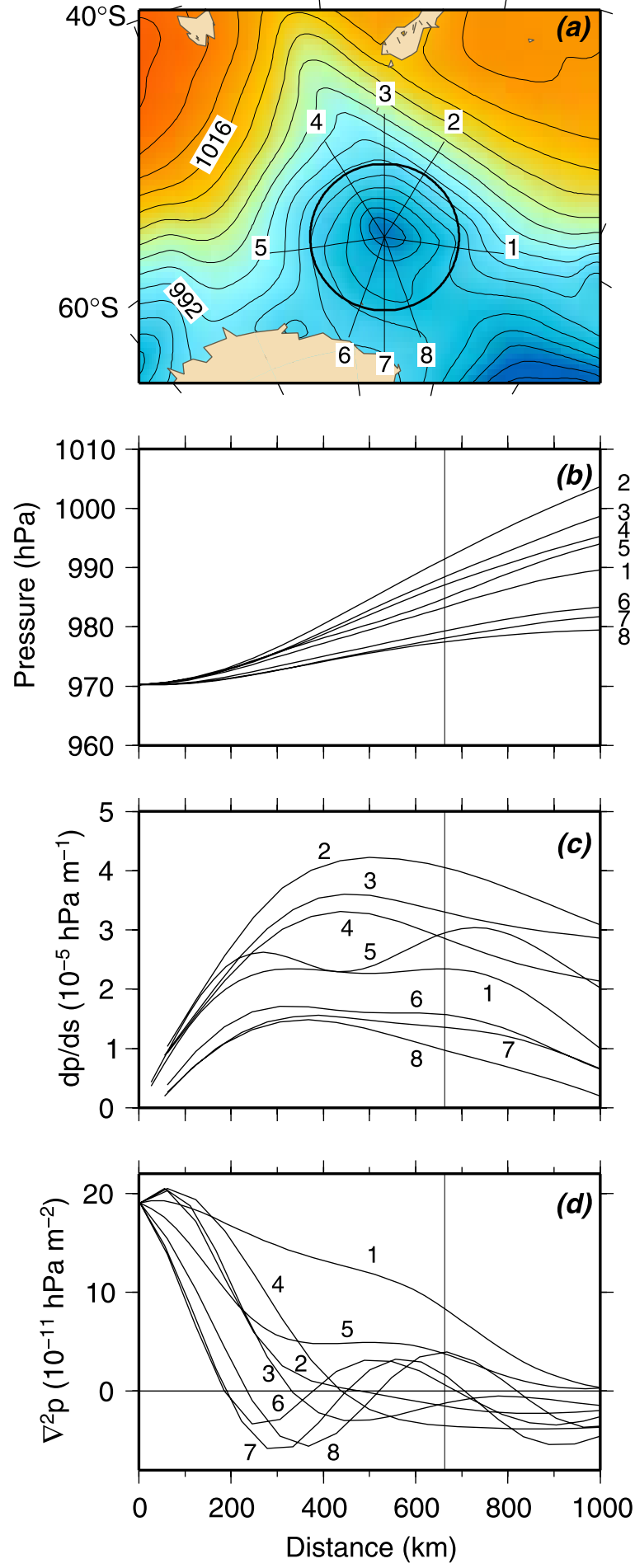

Figure 7. Criteria for the determination of cyclone size. (a) Example of a cyclone south of New Zealand on 26 November 1999, 0000 UTC. Same color scale as in Figure 1 with $4-\mathrm{hPa}$ isobars. The solid lines show the 8 radial lines along which the quantities are calculated (the distortion is due to the Lambert projection). The circle is centered at the pressure minimum and has the selected radius of $664 \mathrm{~km}$. (b) Increase in sea level pressure along eight radial lines. (c) Pressure gradient along radial lines. (d) Laplacian of pressure. The vertical line indicates a radius of $663 \mathrm{~km}$. well qualitatively with, for example, Figure 1a of Murray and Simmonds [1991b] (except for storm positions over land, which are not calculated in this study). Note in particular the concentration of tracks around the oriental flank of Antarctica, between $130^{\circ} \mathrm{E}$ and $170^{\circ} \mathrm{E}$ (roughly along Adélie Land) and the storm tracks originating in the lee of the Andes.

\subsection{Estimation of the Size and Strength of Cyclones}

[26] Our main objective is to quantify the impact of scatterometer data on the characterization of the strength and tracks of midlatitude cyclones. The analysis requires that the "size" of the cyclones be identified from the surface pressure field. There is, however, no easily identified physical or dynamical boundary to a cyclone. The concept of size is very much tied to the specific application one has in mind. Grotjahn et al. [1999] used a wavelet-based method to detect changes in the size of North Pacific lows. Sinclair [1997] defined the end of a cyclonic domain as the boundary at which the gradient of the geostrophic vorticity calculated along radial lines changes sign. Simmonds and Keay [2000b] used a similar method and followed the directions of maximum gradient to reach the boundaries of the cyclonic domain visualized as a "catchment." The method used here borrows from these previous studies and is now illustrated with an example.

[27] Figure 7a shows a midlatitude cyclone in the Southern Ocean on 26 November 1999 at 0000 UTC. Its central pressure is $965 \mathrm{hPa}$ and its cold front extends northward between Tasmania and New Zealand. Figure $7 \mathrm{~b}$ shows that, as we follow radial lines (numbered 1 to 8 ) away from the center, the pressure increases monotonically as we enter the synoptic regions of higher pressure surrounding the cyclone. Pressure is obviously a poor indicator of the cyclone extension, or boundary. The slope of these lines, however, goes through a maximum, as is better seen in Figure 7c. The slope is zero at the center of the cyclone (the center of a low is typically "flat") and relatively small as we move into the surrounding regions of higher pressure (anticyclones are typically flat as well), but is maximum in the region of strong pressure gradient typical of midlatitude cyclones. A simple estimate of the size of the cyclone is the distance from the center to the point at which this radial pressure gradient is maximum. Rudeva and Gulev [2007] use a similar method and calculate 36 such radii, the area contained within the corresponding polygon, and the radius of a circle having the same area as the polygon. They also obtain interesting results by comparing the smallest and largest radii as an indicator of the cyclone asymmetry. Here we choose to simply average the distance over the eight radial lines. Although this method works well, it tends to yield radii that do not capture the whole storm. Specifically, a circle of such radius centered on the low does not encompass all the closed isobars. We therefore select the distance at which the radial pressure gradient decreases below $2.5 \times 10^{-5} \mathrm{hPa} \mathrm{m}^{-1}$ after going through a maximum (if the maximum is less than $2.5 \times 10^{-5} \mathrm{hPa} \mathrm{m}^{-1}$, then that is the selected distance). In the example of Figure 7, the average distance is $663 \mathrm{~km}$, as shown by the circle in Figure $7 \mathrm{a}$ and the vertical lines in Figures $7 \mathrm{~b}, 7 \mathrm{c}$, and $7 \mathrm{~d}$. The specific value of the threshold was determined subjec- 

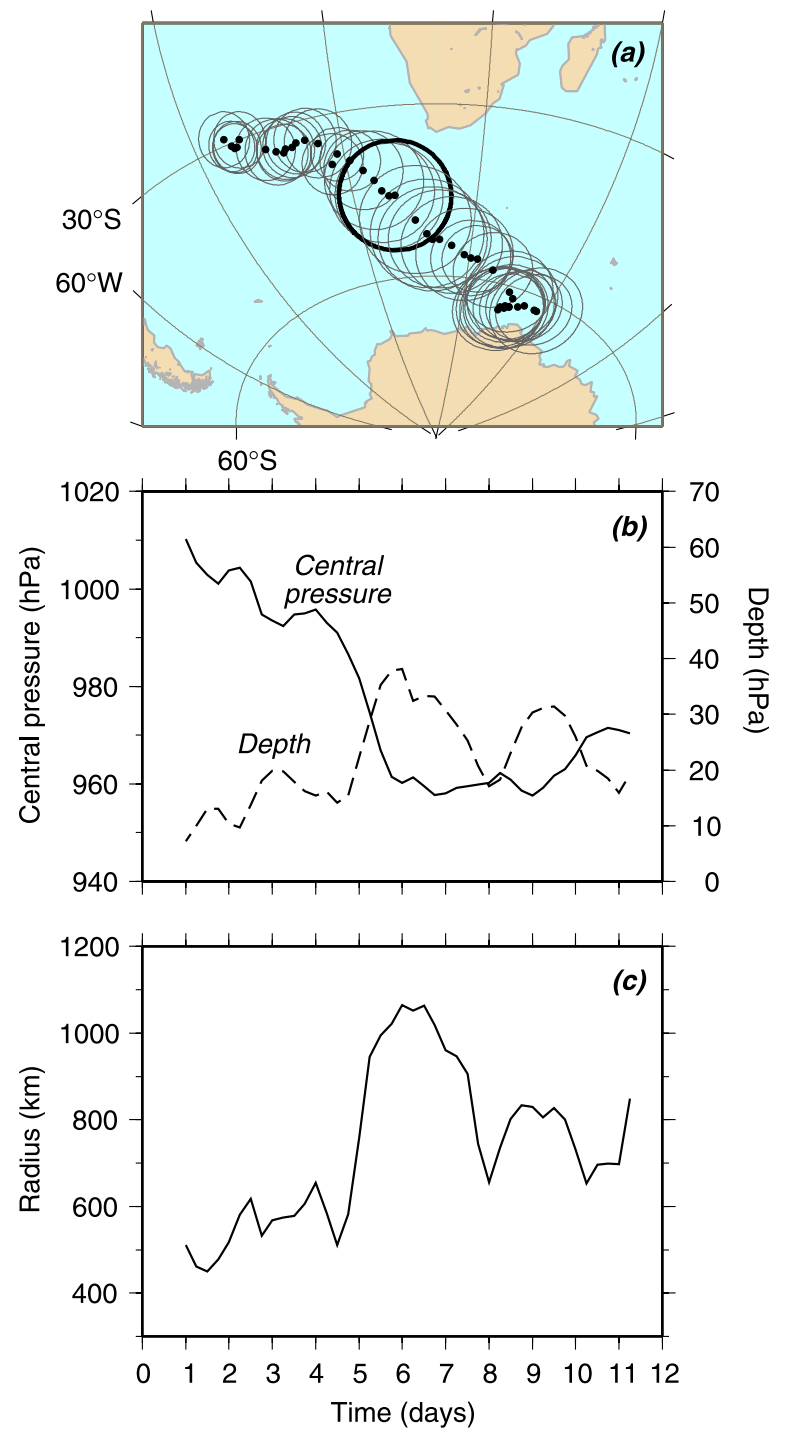

Figure 8. Example of identification of midlatitude cyclone track, central pressure, radius and depth over a full life cycle, 28 July to 7 August 2000. (a) Position and size. The bold circle represents the maximum radius and depth reached on 2 August 2000, 0000 UTC. (b) Central pressure and depth. (c) Radius.

tively by visual inspection of a large series of cyclones in such a way as to ensure that, in each case, the circle encloses at least all closed isobars, reaches the closest col point, and captures the bulk of the air-sea fluxes in the storm. (The size of the cyclones in relation to the corresponding fluxes of heat and momentum will be discussed in more detail in part 2 [Yuan et al., 2009].) For reference, Figure 7d shows the Laplacian of pressure along radial lines, which was found to be noisier (second derivative) and less useful than the gradient.

[28] It is important to remember, as we carry this analysis along, that there is no such thing as a literal "radius" of the storm. A midlatitude cyclone is rarely axisymmetric, and in fact departs drastically from a circular shape when a cold or a warm front, or both, extend from the center into troughs of low pressure. The radius of a cyclone is therefore not to be thought of as "the" definite measure of the size of a cyclone, but as "a" measure of its size. (See also the discussion by Simmonds [2000] and Simmonds and Keay [2000b].) Because our ultimate goal is to compare the size of cyclones in two different data sets, we are content with this measure, knowing that we are using the same measure in both cases.

[29] As we reach the critical distance on each radial line, we also record the value of the surface pressure at that point and average the eight values to obtain an estimate of the pressure surrounding the storm. We define the depth of a cyclone as the difference between that average surrounding pressure and the pressure at the center. The depth is sometimes called the "pressure deficit" and is closely related to the intensity of the cyclone, as can be seen with the following simplified model.

[30] Figure 7b suggests that the pressure field inside a cyclone out to the radius $R$ can be approximately modeled as a paraboloid defined in cylindrical coordinates $(r, \theta)$ as

$$
p(r)=\frac{r^{2}}{R^{2}} d+p_{c} \quad 0 \leq r \leq R,
$$

where $p$ is the sea-level pressure, $d$ is the depth defined above, and $p_{c}$ is the central pressure. If we make a geostrophic balance approximation, then the wind is given by

$$
\begin{aligned}
& u_{r}=-\frac{1}{\rho f} \frac{\partial p}{r \partial \theta}=0 \\
& u_{\theta}=\frac{1}{\rho f} \frac{\partial p}{\partial r}=\frac{2 d}{\rho f R^{2}} r
\end{aligned}
$$

where $u_{r}$ and $u_{\theta}$ are the radial and tangential wind components respectively, $\rho$ is the air density, and $f$ is the Coriolis parameter (both assumed constant). The vorticity is then

$$
\zeta=\frac{1}{r} \frac{\partial\left(r u_{\theta}\right)}{\partial r}-\frac{1}{r} \frac{\partial u_{r}}{\partial \theta}=\frac{4 d}{\rho f R^{2}}
$$

and is independent of $r$ and $\theta$. If, following Sinclair [1997], we define the intensity of the storm as the integral of the vorticity over the area of the storm, then the intensity is

$$
I=\int_{A} \zeta d A=\frac{4 d}{\rho f R^{2}} \pi R^{2}=\frac{4 \pi d}{\rho f}
$$

and is proportional to the depth. Therefore, radius, depth, and intensity go hand in hand and will be used as a comparative measure in this analysis. Our definition is very similar to that used by Simmonds and Keay [2000b] and Sinclair [1997].

[31] An example of a complete life cycle is shown in Figure 8 for a midlatitude cyclone passing the Cape of Good Hope toward Antarctica between 28 July and 7 August 2000. As the central pressure drops from $1010 \mathrm{hPa}$ to $960 \mathrm{hPa}$ over 5 days, the depth increases from $8 \mathrm{hPa}$ to 

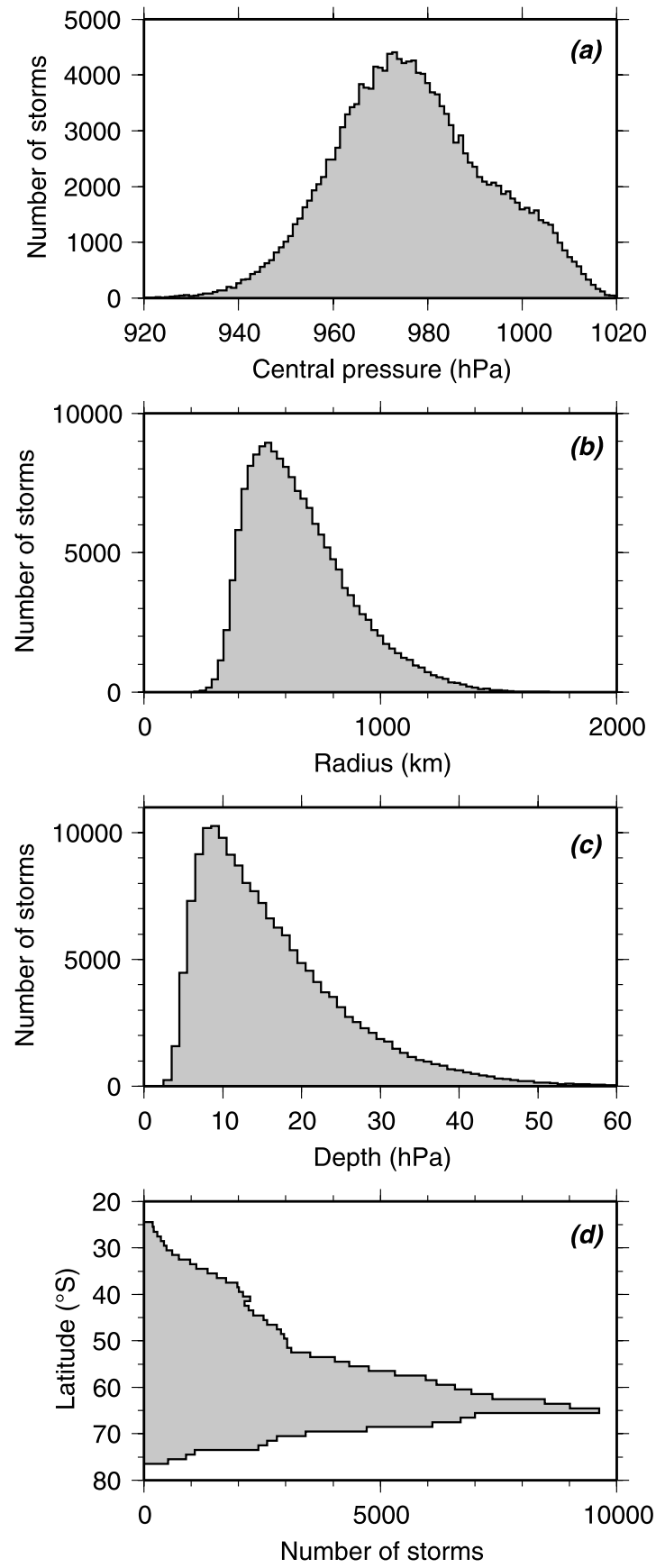

Figure 9. Seven-year histograms of the distribution of Southern Ocean storms as a function of (a) central pressure, (b) radius, (c) depth, and (d) latitude.

$38 \mathrm{hPa}$ while the radius increases from 450 to $1050 \mathrm{~km}$. Note that the strong correlation between depth and radius is consistent with the definition we have adopted for those two quantities. More statistics are now presented.

\section{Results}

[32] This section provides general statistics about the cyclones detected over the Southern Ocean. We will then evaluate the impact of the scatterometer-derived pressure fields on the representation of Southern Ocean cyclones as characterized by their track, life span, central pressure, size, and depth.

\subsection{General Statistics}

[33] Figure 9 contains 7-year histograms of the frequency of cyclones sorted by central pressure, size, depth, and latitude, as determined from the ECMWF surface pressure analyses. All occurrences are counted, which means that a cyclone with a 5-day life span (i.e., 21 synoptic periods) is represented by 21 points, each point corresponding to a distinct stage of the cyclone. The distribution of central pressures is roughly bell-shaped around a peak of $973 \mathrm{hPa}$ with a slight bulge between 990 and $1020 \mathrm{hPa}$. It reveals a few cyclones with extremely low central pressures (less than $930 \mathrm{hPa}$ ). We have verified that they usually occur between $50^{\circ} \mathrm{S}$ and $70^{\circ} \mathrm{S}$ (not shown). Cyclones with radius greater than $1500 \mathrm{~km}$ also occur in the same latitude band. Depressions with high central pressure (more than $1020 \mathrm{hPa}$ ) do exist but are filtered out by the selection scheme owing to a lack of significant vorticity. This filtering also partly explains the skewness to the right of the radius distribution (peak at $525 \mathrm{~km}$ ) and of the depth distribution (peak at $9 \mathrm{hPa}$ ). Shallow depressions with a smaller radius do exist but are not captured by the selection scheme because their cyclonic vorticity is too small. Finally, a large majority of the cyclones occur between $50^{\circ} \mathrm{S}$ and $75^{\circ} \mathrm{S}$ with a clear peak at $65^{\circ} \mathrm{S}$.

[34] The first three histograms are strongly dependent on latitude. We expect a greater number of cyclones in the storm track region. To show that latitude dependency, we have plotted the median, upper and lower quartiles, as well as the upper and lower 95th percentiles of these histograms as a function of latitude in Figure 10. The central pressure is maximal around $35^{\circ} \mathrm{S}$ and minimal around $65^{\circ} \mathrm{S}$ with a broader distribution at higher latitudes. The median and spread of the radius and depth distributions are both maximal at $65^{\circ} \mathrm{S}$.

[35] Figure 11 shows the relationship between central pressure, radius, and depth in three different scatterplots (all occurrences are counted as well; see above). The regions of highest concentration of points are consistent with the peak values determined from the previous histograms. The clouds of points in Figures 11a and 11 c bulge to the bottom left, indicating that there exists a significant number of smaller cyclones (smaller radius, and consequently smaller depth) with low central pressure. These form at higher latitudes in the polar trough and are embedded in an environment where the overall pressure is low (e.g., polar lows). Consequently, the central pressure is even lower, but they are not necessarily very large or very deep. The reverse is, of course, not true: cyclones that have a relatively high central pressure are neither deep nor large, which explains why there are no points in the upper right sector of Figures $11 \mathrm{a}$ and $11 \mathrm{c}$. As mentioned earlier, radius and depth are intimately related, which explains that the cloud of points in Figure $11 \mathrm{~b}$ is narrower and shows no bulge.

[36] The same search performed with the same criteria on the UWPBL surface pressure fields consistently yields a larger number of depressions by 5 to $10 \%$ depending on the 

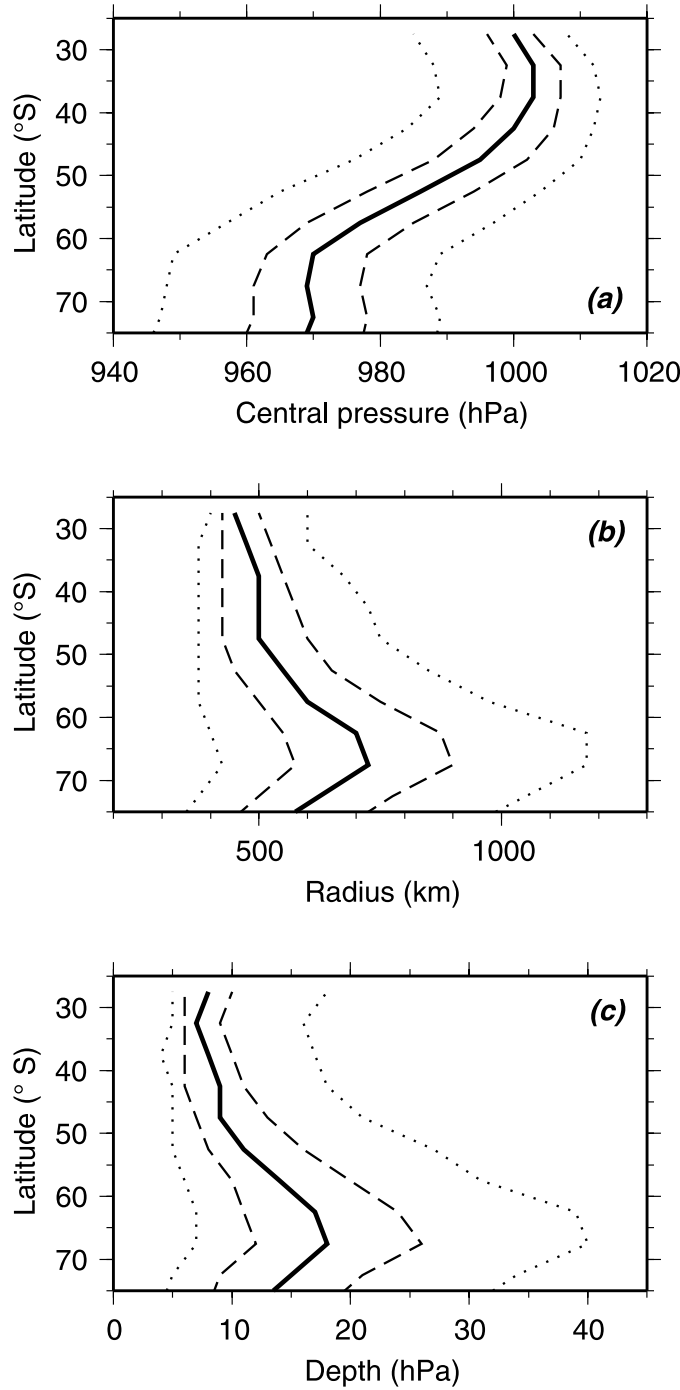

Figure 10. Median (solid lines), upper, and lower quartiles (dashed line) and upper and lower 95th percentiles (dotted line) of the frequency distributions of storms as a function of latitude. (a) Central pressure. (b) Radius. (c) Depth.

year and season. However, caution must be exercised when interpreting this number. These additional depressions are not all "new" storms that are completely absent from the ECMWF analyses and present in the scatterometer pressure swaths. They are cyclonic circulations with either stronger pressure gradients or higher vorticity (or both) in the UWPBL data set that pass the threshold of the selecting scheme. Most do exist in the ECMWF surface analyses, but are either weaker or not well characterized in structure, as the following example will illustrate.

\subsection{Enhancement of Storm Tracks}

[37] The methodology is now assessed by identifying storm tracks that are longer after the UWQS pressure swaths have been incorporated into the ECMWF pressure fields. Because it is very unlikely that an erroneous depression be present in the vicinity of a storm 6 or 12 hours prior to the incipient low or after the decaying stage, a longer track means that the scatterometer has effectively captured a relevant feature and adds valuable information about either the incipient stage or the mature stage of the cyclone. This is therefore a good test of the value added in the UWPBL pressure fields. Figure 12a shows an example of such a longer track east of the Antarctic peninsula and Drake Passage. The cyclone is detected $12 \mathrm{~h}$ earlier (i.e., two synoptic periods earlier) in the UWPBL pressure fields, as
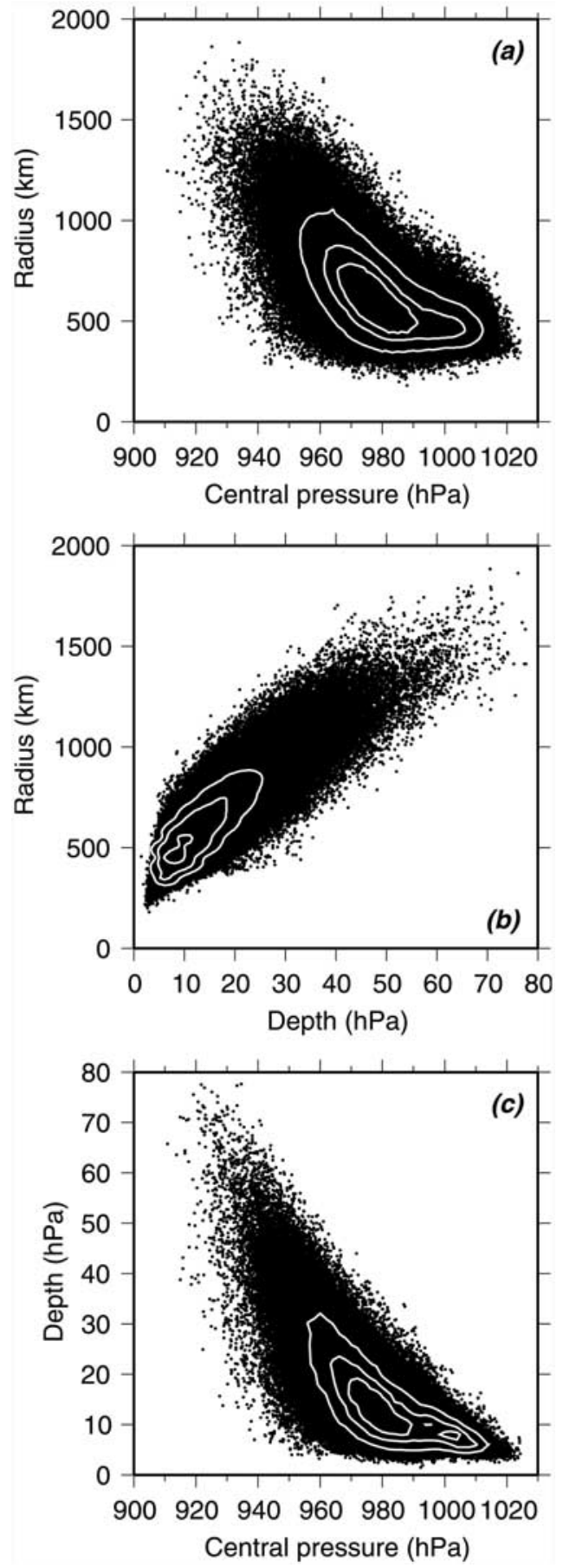

Figure 11. Seven-year scatterplots of the distribution of Southern Ocean storms. (a) Radius versus central pressure. (b) Radius versus depth. (c) Depth versus central pressure. The solid white lines enclose $25 \%, 50 \%$, and $75 \%$ of the data points. 

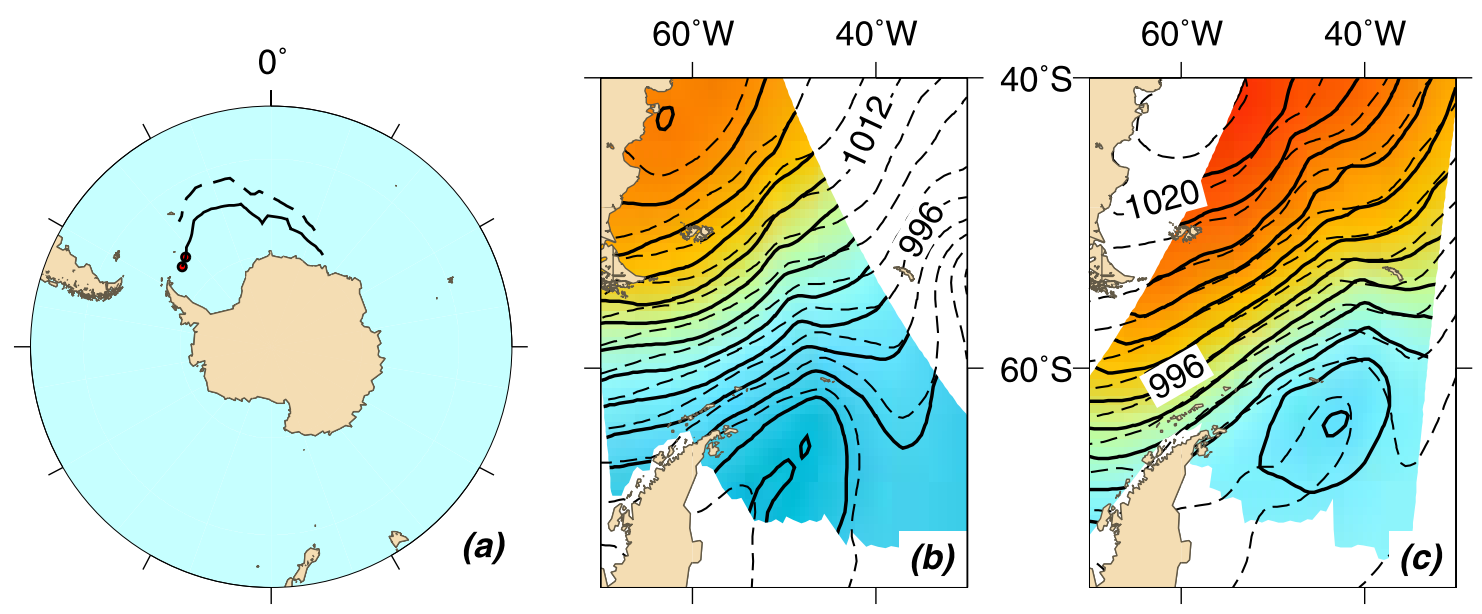

Figure 12. Example of a cyclone track extended by $12 \mathrm{~h}$ when using the blended surface pressure fields. (a) Comparison of the ECMWF track (dashed line shifted north by a few degrees for comparison) and the track obtained from the blended fields. Black dots indicate the two new positions in the track. (b) ECMWF sea level pressure (dashed line) and QS pressure swath (solid line) on 16 February 2002, 1200 UTC. (c) Same on 16 February 2002, 1800 UTC. Same color scale as in Figure 1.

shown in Figure 12a by the two black dots. The pressure fields at those two synoptic times are shown in Figures $12 \mathrm{~b}$ and 12c. It is apparent that at 1200 UTC, the ECMWF analysis suggests a broad trough east of the peninsula while the UWQS pressure swath suggests a narrow frontal region on which a small closed low is already detectable. At 1800 UTC, the UWQS low is well formed with two closed isobars while ECMWF still suggests an open trough. By 0000 UTC on 17 January, ECMWF has caught up with QS (possibly from assimilating satellite information about the low) and the two tracks are similar. In such cases there is little doubt that the UWPBL information is representative of a real incipient low. We verified that the original QS winds indeed contained a cyclonic circulation in both cases (not shown).

[38] A comparative tracking analysis over the 7-year study period yields the following results: (1) 663 UWPBL tracks $(7.9 \%$ of all tracks) were initiated at least 6 hours earlier than ECMWF; (2) among these, 30 UWPBL tracks $(0.4 \%)$ were initiated 12 hours earlier; (3) 557 UWPBL tracks $(6.7 \%)$ were prolonged by at least 6 hours; (4) among these, 25 UWPBL tracks $(0.4 \%)$ were prolonged by 12 hours and 2 were prolonged by 18 hours; and (5) 83 UWPBL tracks $(1.0 \%)$ were both initiated and prolonged by 6 hours. (Here 6-hour tracks have been discarded and only the cyclones lasting 12 hours (i.e., three synoptic times) or more are considered.) There does not appear to be a preferred geographic location or preferred year for the new UWPBL low-pressure centers (not shown). Figure 13 shows in more detail how the life span distribution is affected by the injection of UWQS pressure swaths. Figure 13a shows the 663 tracks that were initiated earlier in the UWPBL data set, whereas Figure 13b shows the 557 tracks that were extended at the mature stage. In both cases the number of tracks decreases exponentially from a maximum at $12 \mathrm{~h}$ down to very few tracks longer than 10 days, in agreement with Figure 9a of Simmonds and Keay [2000b]. The injection of UWQS pressure swaths shifts the distribution to the right. It is important to note that the scheme does not only affect the tracks of very short life span, but all tracks with no preference for a particular duration.

[39] Another query consists in identifying UWPBL tracks that are absent from the ECMWF database. Figure 14 shows the difference in the number of tracks identified from the two data sets, as a function of life span, for cyclones lasting at least $24 \mathrm{~h}$, and over the 7-year study period. A higher
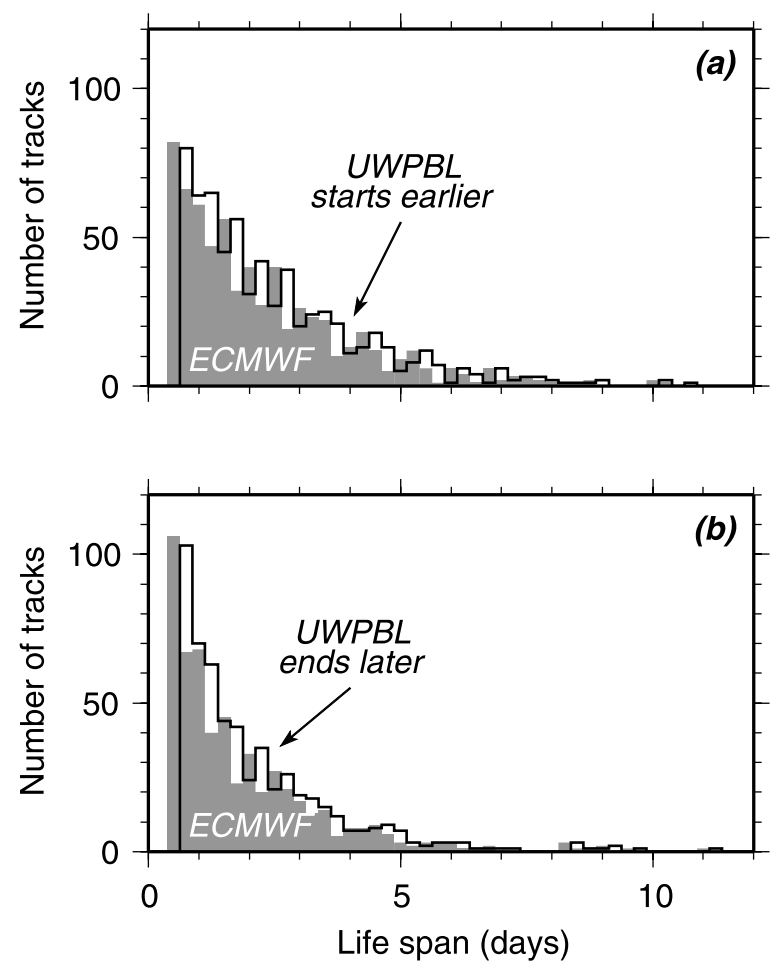

Figure 13. Impact of UWPBL cyclone centers on the distribution of cyclone life spans. Gray is ECMWF. Black outline is UWPBL. (a) Cyclone tracks initiated earlier in UWPBL data set. (b) Cyclone tracks ending later in UWPBL data set. 


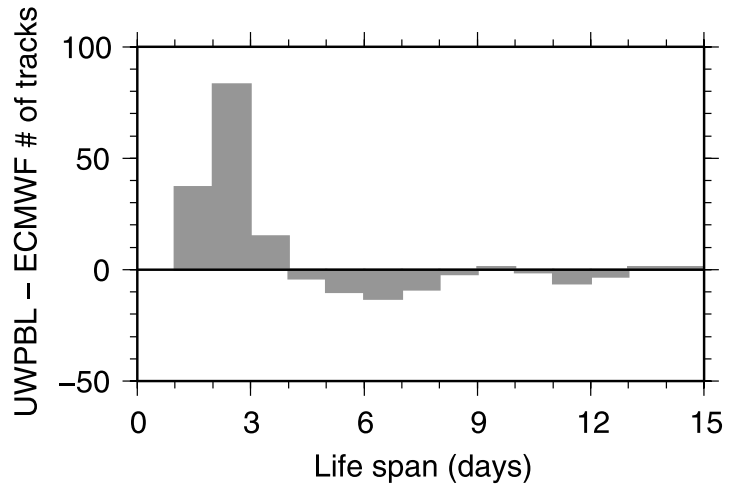

Figure 14. Difference between the number of cyclone tracks in the UWPBL and ECMWF database as a function of life span.

number of short-lived cyclones (less than 4 days in duration) is detected in the UWPBL database. They are typically small depressions that appear in or behind a frontal region, such as polar lows, or in the wake of a major cyclone, and are not immediately captured by ECMWF. They will be discussed more extensively by Yuan et al. [2009].

[40] Note that a small number of the longer ECMWF tracks (more than 4 days) have been broken down into shorter UWPBL tracks. This discrepancy arises from the fact that some lows weaken below the identification threshold after QS injection, which reduces the track length. The weakening might be due to a real decrease in cyclone intensity captured by the scatterometer, or to noise in the QS winds organized on a spatial scale similar or greater than the smoothing and spatial constraints used herein. However, the number of additional UWPBL shorter tracks is significantly greater than the number of shortened long tracks.

\subsection{Cyclone Characteristics}

[41] The final comparison consists in evaluating the differences in central pressure, radius, and size between the ECMWF and the UWPBL cyclone tracks, as summarized in Figure 15. The 1999-2006 distributions are very narrow and peaked, resulting in a 0 median in all cases, and very small quartiles $(0.1 \mathrm{hPa}$ central pressure difference at $60^{\circ} \mathrm{S}$ and $0.2 \mathrm{hPa}$ depth difference at $55^{\circ} \mathrm{S}$ ), which suggests that a large majority of the cyclones are very similar in the two databases. The 95 th percentiles indicate that the differences are usually less than $3 \mathrm{hPa}$ in central pressure and depth and $70 \mathrm{~km}$ in radius. The mean and the skewness of the distributions suggest that the UWPBL cyclones are slightly deeper than ECMWF with a maximum mean difference of $0.3 \mathrm{hPa}$ around $45^{\circ} \mathrm{S}-55^{\circ} \mathrm{S}$ and maximum 95th percentiles of $3 \mathrm{hPa}$ around $55^{\circ} \mathrm{S}$. Similar differences with NWP model forecasts were observed at the NOAA Ocean Prediction Center [Von Ahn et al., 2006a, 2006b] in the Northern Hemisphere. Much larger differences are exceptional, but strongly impact weather forecasts when they occur. The impact of these differences between the ECMWF and UWPBL cyclone tracks on the calculation of air-sea fluxes will be assessed in part 2 [Yuan et al., 2009].

\subsection{Spectral Analysis}

[42] The final evaluation of the UWPBL pressure fields consists in performing a parallel spectral decomposition on both surface pressure products: ECMWF and UWPBL. A difference in the resulting spectra will indicate the wavenumbers at which the scatterometer is adding or subtracting energy.

[43] We compute the power spectral density on a longitude-latitude grid of dimension $N_{1} \times N_{2}$ where $N_{1}=60$ between $160^{\circ} \mathrm{W}$ and $220^{\circ} \mathrm{W}$, and $N_{2}=30$ between $60^{\circ} \mathrm{S}$ and $30^{\circ} \mathrm{S}$ (southern Pacific Ocean). Although the zonal grid size is a function of latitude, we choose to neglect the effects due to the spherical shape of the Earth and to concentrate on the differences between the ECMWF and UWPBL spectra. The latitudinal extent of the grid is $3388 \mathrm{~km}$, which translates into a latitudinal wavenumber resolution of $0.000295 \mathrm{~km}^{-1}$ $(3388 \mathrm{~km})$ to $0.008856 \mathrm{~km}^{-1}(113 \mathrm{~km})$. The longitudinal extent varies from $5868 \mathrm{~km}$ at $30^{\circ} \mathrm{S}$ to $3388 \mathrm{~km}$ at $60^{\circ} \mathrm{S}$, which translates into a longitudinal wavenumber resolution of $0.000170 \mathrm{~km}^{-1}(5868 \mathrm{~km})$ to $0.010204 \mathrm{~km}^{-1}(98 \mathrm{~km})$ at $30^{\circ} \mathrm{S}$ and $0.000295 \mathrm{~km}^{-1}(3388 \mathrm{~km})$ to $0.017544 \mathrm{~km}^{-1}$ $(57 \mathrm{~km})$ at $60^{\circ} \mathrm{S}$.

[44] Figure 16 shows the resulting mean spectrum averaged over the 1999-2006 QS period. Figure 16a shows the
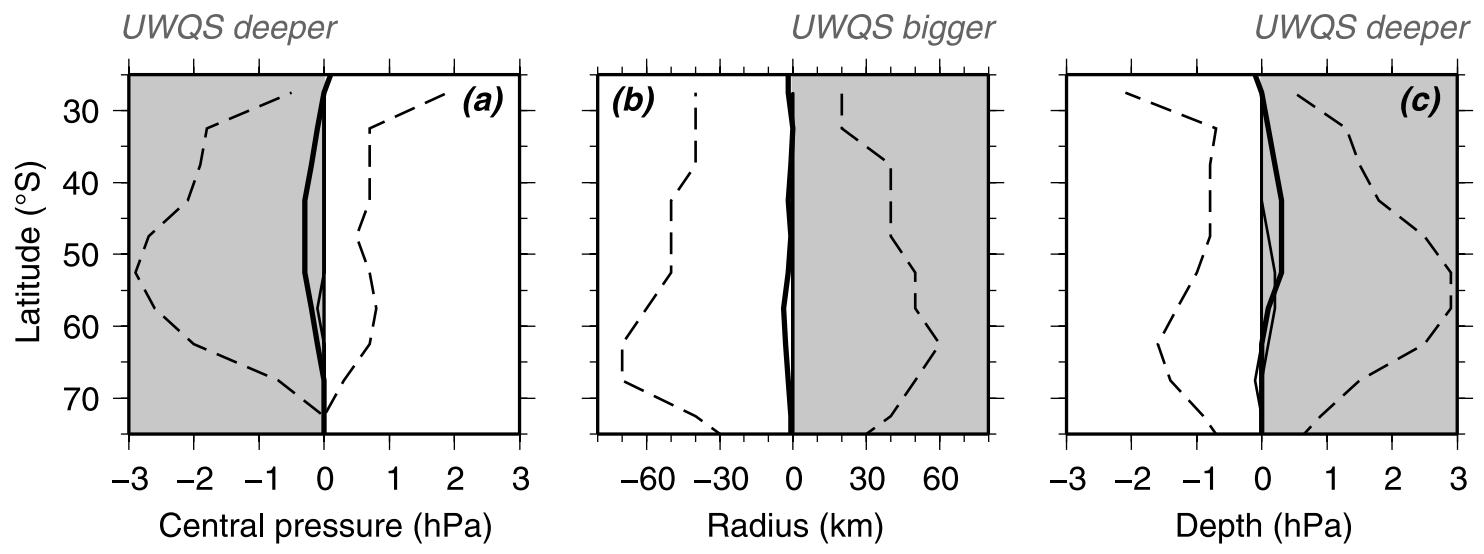

Figure 15. Mean (solid thick line), median (solid thin line, equal to 0), upper and lower quartiles (solid thin line), and upper and lower 95th percentiles (dashed line) of the distribution of UWPBL-ECMWF differences in (a) central pressure, (b) radius, and (c) depth for the 1999-2006 period. 

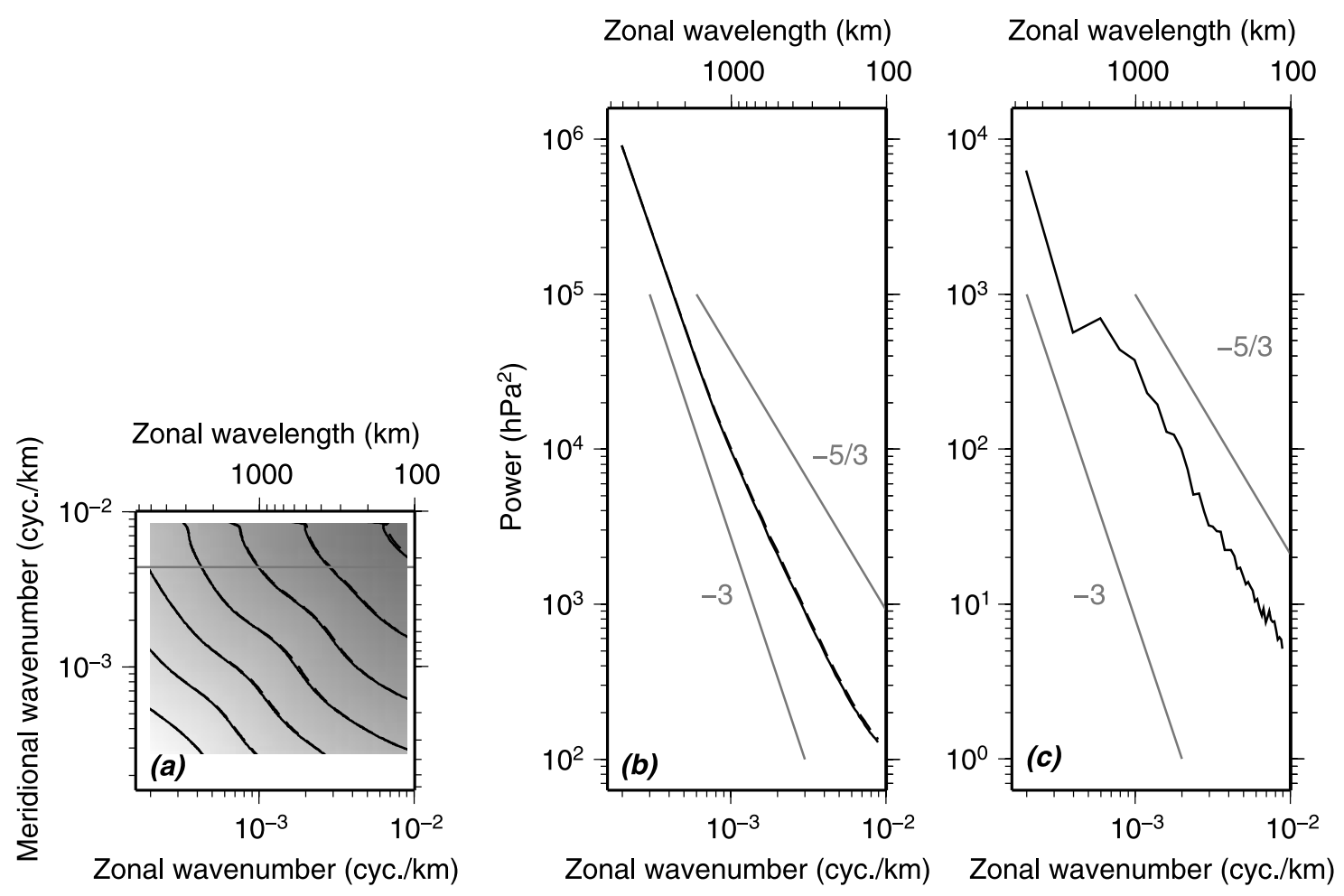

Figure 16. Spectral decomposition of the ECMWF (solid lines) and UWPBL (dashed lines) surface pressure fields over the Southern Pacific Ocean averaged over the 1999-2006 period. (a) Twodimensional decomposition. (b) Cross section of Figure 16a at the 226-km meridional wavelength (indicated by the gray line in Figure 16a for reference). (c) Power difference between the UWPBL and ECMWF spectra shown in Figure 16b. Note the 2-order magnitude change in the y axis between Figures $16 \mathrm{~b}$ and $16 \mathrm{c}$. The $-5 / 3$ and -3 slope are indicated for reference.

two-dimensional decomposition where the bottom left part of the spectrum (lighter gray) corresponds to large wavelengths, whereas the top right corner (darker gray) corresponds to short wavelengths (high wavenumbers). Figure $16 \mathrm{~b}$ is a cross section of the two-dimensional spectrum where the meridional wavenumber is held constant at $226 \mathrm{~km}$, as shown by the gray line in Figure 16a. The $-5 / 3$ and -3 slopes are indicated for reference. The mean spectra are qualitatively consistent with the swath-based surface pressure spectra described by Patoux et al. [2008]. A slope of about -2.90 is observed at wavelengths greater than about $2000 \mathrm{~km}$. Below $2000 \mathrm{~km}$, the spectrum is less steep with a slope of -1.97 . Figure $16 \mathrm{c}$ is of special interest in this analysis. It shows the difference between the two spectra (UWPBL-ECMWF) from Figure 16b. Note the 2-order magnitude difference in power on the $y$ axis. The UWPBL spectrum contains about $1 \%$ more energy at all wavelengths. Note that the slope of the difference spectrum is close to $-5 / 3$, which suggests that the additional UWPBL energy blended into the ECMWF pressure analyses might correspond to small-to-mesoscale structures whose energy is being transferred "upward" to larger scales by an inverse energy cascade [Wikle et al., 1999; Patoux and Brown, 2001].

\section{Concluding Remarks}

[45] A wavelet-based method is described to blend scatterometer-derived surface pressure swaths into ECMWF analyses. The resulting modified pressure fields are used to identify and track midlatitude cyclones over the Southern Ocean, as well as to estimate the size and depth of the cyclones at each stage of their life cycle. The cyclone statistics are compared to the reference statistics built from the original ECMWF analyses. It is noted that the cyclone selection scheme is sensitive to the thresholds used for vorticity and depth in determining whether a given depression is a significant cyclonic circulation. Lower thresholds would increase the number of storm positions in each data set (although not necessarily the number of tracks). However, because the same thresholds are applied to both ECMWF and UWPBL surface pressure fields, a comparison of the resulting cyclone positions and cyclone tracks constitutes a good assessment of the impact of the mesoscale to synoptic-scale scatterometer information on the intensity and structure of the cyclones.

[46] In the modified 7-year cyclone statistics, 1137 tracks have been extended by at least one synoptic period, at the incipient stage, mature stage, or both. The modified cyclones are slightly deeper on average than the ECMWF cyclones with a maximum mean difference of $0.3 \mathrm{hPa}$ around $45^{\circ} \mathrm{S}-$ $55^{\circ} \mathrm{S}$. The impact of these differences on momentum and heat fluxes at the air-sea interface will be assessed in part 2 [Yuan et al., 2009]. These differences should be viewed in light of the limitations of the blending method (partial blending of the scatterometer information, time lag, edge effects). They suggest that a better assimilation method, such as 3DVAR, might have a stronger impact. A future extension of this project will consist in assimilating the UWQS pressure 
swaths into the Weather Research and Forecasting (WRF) model using a state-of-the-art assimilation scheme, and assessing their impact on forecasting skill.

[47] Acknowledgments. We would like to thank Ian Simmonds and Kevin Keay for their assistance in providing us with their algorithms and helping us with their implementation; Charles Cornish for helping us with the wavelet decomposition; Ralph Milliff, Michael Chin, Bertrand Chapron and Yves Quilfen for their encouragements and insightful comments; as well as two anonymous reviewers for their input and suggestions. The ds111.1 data were provided by ECMWF through the Data Support Section of the Computational and Information Systems Laboratory at the National Center for Atmospheric Research. NCAR is supported by grants from the National Science Foundation. Patoux acknowledges NASA OVWST grant support under JPL subcontract 1285663 . Yuan and Li were supported by the National Science Foundation through grants OPP02300284 and ANT $07-32656$, and by NASA OVWST through grant JPLCIT-1216483. Lamont publication 7226

\section{References}

Atlas, R., S. Bloom, R. N. Hoffman, E. Brin, J. Ardizzone, J. Terry, D. Bungato, and J. C. Jusem (1999), Geophysical validation of NSCAT winds using atmospheric data and analyses, J. Geophys. Res., 104(C5), $11,405-11,424$

Blender, R., K. Fraedrich, and F. Lunkeit (1997), Identification of cyclone track regimes in the North Atlantic, Q. J. R. Meteorol. Soc., 123, 727-741.

Brown, R. A. (1982), On two-layer models and the similarity functions for the planetary boundary layer, Boundary Layer Meteorol., 24, 451-463.

Brown, R. A., and G. Levy (1986), Ocean surface pressure fields from satellite sensed winds, Mon. Weather Rev, 114, 2197-2206.

Brown, R. A., and L. Zeng (1994), Estimating central pressures of oceanic mid-latitude cyclones, J. Appl. Meteorol., 33, 1088-1095.

Carleton, A. M. (1983), Variations in Antarctic sea ice conditions and relationships with Southern Hemisphere cyclone activity, winter $1973-$ 77, Arch. Meteorol. Geophys. Bioklimatol., Ser. B, 32, 1-22.

Carleton, A. M., and D. A. Carpenter (1989), Intermediate-scale seaice-atmosphere interactions over high southern latitudes in winter, GeoJournal, 18, 87-101.

Carleton, A. M., and D. A. Carpenter (1990), Satellite climatology of polar lows and broadscale climatic associations for the Southern Hemisphere, Int. J. Climatol., 10, 219-246.

Carleton, A. M., and M. Fitch (1993), Synoptic aspects of Antarctic mesocyclones, J. Geophys. Res., 98(D7), 12,997-13,018.

Carrasco, J. F., and D. H. Bromwich (1993), Mesoscale cyclogenesis dynamics over the southwestern Ross Sea, Antarctica, J. Geophys. Res., 98(D7), 12,973-12,995.

Chelton, D. B. (2005), The impact of SST specification on ECMWF surface wind stress fields in the eastern tropical Pacific, J. Clim., 18, 530-550.

Chelton, D. B., and M. H. Freilich (2005), Scatterometer-based assessment of 10-m wind analyses from the operational ECMWF and NCEP Numerical Weather Prediction models, Mon. Weather Rev., 133, 409-429.

Chelton, D. B., S. K. Esbensen, M. G. Schlax, N. Thum, M. H. Freilich, F. J. Wentz, C. L. Gentemann, M. J. McPhaden, and P. S. Schopf (2001), Observations of coupling between surface wind stress and sea surface temperature in the eastern tropical Pacific, J. Clim., 14, 1479-1498.

Chelton, D. B., M. H. Freilich, J. M. Sienkiewicz, and J. V. Ahn (2006), On the use of QuikSCAT scatterometer measurements of surface winds for marine weather prediction, Mon. Weather Rev., 134, 2055-2071.

Chin, T. M., R. F. Milliff, and W. G. Large (1998), Basin-scale, highwavenumber sea surface wind fields from a multiresolution analysis of scatterometer data, J. Atmos. Oceanic Technol., 15, 741-763.

Condron, A., G. R. Bigg, and I. A. Renfrew (2006), Polar mesoscale cyclones in the northeast Atlantic: Comparing climatologies from ERA-40 and satellite imagery, Mon. Weather Rev., 134, 1518-1533.

Fitch, M., and A. M. Carleton (1992), Antarctic mesocyclone regimes from satellite and conventional data, Tellus, Ser. A, 44, 180-196.

Foster, R. C., R. A. Brown, and A. Enloe (1999), Baroclinic modifications of midlatitude marine surface wind vectors observed by the NASA scatterometer, J. Geophys. Res., 104(D24), 31,225-31,237.

Foufoula-Georgiou, E., and P. Kumar (1994), Wavelets in Geophysics, 373 pp., Academic Press, San Diego, Calif.

Grotjahn, R., D. Hodyss, and C. Castello (1999), Do frontal cyclones change size? Observed widths of North Pacific lows, Mon. Weather Rev., 127, 1089-1095.

Hanson, C. E., J. P. Palutikof, and T. D. Davies (2004), Objective cyclone climatologies of the North Atlantic-A comparison between the ECMWF and NCEP reanalyses, Clim. Dyn., 22, 757-769.
Harlan, J., and J. J. O'Brien (1986), Assimilation of scatterometer winds into surface pressure fields using a variational method, J. Geophys. Res., 91(D7), 7816-7836.

Heinemann, G. (1990), Mesoscale vortices in the Weddell Sea region (Antarctica), Mon. Weather Rev., 118, 779-793.

Hewson, T. (1997), Objective identification of frontal wave cyclones, Meteorol. Appl., 4, 311-315.

Hilburn, K. A., M. A. Bourassa, and J. O'Brien (2003), Development of scatterometer-derived research-quality surface pressures for the Southern Ocean, J. Geophys. Res., 108(C7), 3244, doi:10.1029/2003JC001772.

Hodges, K. I. (1995), Feature tracking on the unit sphere, Mon. Weather Rev., 123, 3458-3465.

Hodges, K. I. (1999), Adaptive constraints for feature tracking, Mon Weather Rev., 127, 1362-1373.

Hsu, C. S., and W. T. Liu (1996), Wind and pressure fields near tropical cyclone Oliver derived from scatterometer observations, J. Geophys. Res., 101(D12), 17,021-17,027.

Hsu, C. S., M. G. Wurtele, G. F. Cunningham, and P. M. Woiceshyn (1997), Construction of marine surface pressure fields from scatterometer winds alone, J. Appl. Meteorol., 36, 1249-1261.

Huddleston, J. N., and B. W. Stiles (2000), A multidimensional histogram rain-flagging technique for seawinds on QuikSCAT, paper presented at Geoscience and Remote Sensing Symposium, Inst. of Electr. and Electron. Eng., Honolulu, Hawaii.

König, W., R. Sausen, and F. Sielmann (1993), Objective identification of cyclones in GCM simulations, J. Clim., 6, 2217-2231.

Lambert, S. J. (1988), A cyclone climatology of the Canadian Climate Centre general circulation model, J. Clim., 1, 109-115.

Levy, G. (1994), Southern Hemisphere low level wind circulation statistics from the Seasat scatterometer, Ann. Geophys., 12, 65-79.

Levy, G., and R. A. Brown (1991), Southern Hemisphere synoptic weather from a satellite scatterometer, Mon. Weather Rev., 119, 2803-2813.

Liu, W. T. (2002), Progress in scatterometer application, J. Oceanogr., 58, $121-136$.

Marshall, G., and J. Turner (1999), Synoptic-scale weather systems observed during the FROST project via scatterometer winds, Weather Forecasting, $14,867-877$

Milliff, R. F., M. Freilich, W. Liu, R. Atlas, and W. Large (2002), Global ocean surface vector wind observations from space, in Observing the Oceans in the 21 st Century, edited by C. J. Koblinsky and N. R. Smith, pp. 102-119, GODAE Proj. Off., Melbourne, Victoria, Australia.

Murray, R. J., and I. Simmonds (1991a), A numerical scheme for tracking cyclone centres from digital data. Part I: Development and operation of the scheme, Aust. Meteorol. Mag., 39, 155-166.

Murray, R. J., and I. Simmonds (1991b), A numerical scheme for tracking cyclone centres from digital data. Part II: Application to January and July General Circulation Model simulations, Aust. Meteorol. Mag., 39, $167-180$.

O'Neill, L. W., D. B. Chelton, and S. K. Esbensen (2005), High-resolution satellite measurements of the atmospheric boundary layer response to SST variations along the Agulhas Return Current, J. Clim., 18, 27062723.

Patoux, J., and R. A. Brown (2001), Spectral analysis of QuikSCAT surface winds and two-dimensional turbulence, J. Geophys. Res., 106(D20), 23,995-24,005.

Patoux, J., and R. A. Brown (2002), A gradient wind correction for surface pressure fields retrieved from scatterometer winds, J. Appl. Meteorol., 41, $133-143$.

Patoux, J., R. C. Foster, and R. A. Brown (2003), Global pressure fields from scatterometer winds, J. Appl. Meteorol., 42, 813-826.

Patoux, J., G. J. Hakim, and R. A. Brown (2005), Diagnosis of frontal instabilities over the Southern Ocean, Mon. Weather Rev., 133, 863-875.

Patoux, J., R. C. Foster, and R. A. Brown (2008), An evaluation of scatterometer-derived oceanic surface pressure fields, J. Appl. Meteorol. Climatol., 47, 835-852.

Peixoto, J. P., and A. H. Oort (1992), Physics of Climate, 520 pp., Am. Inst. of Phys., College Park, Md.

Percival, D. B., and A. T. Walden (2000), Wavelet Methods for Time Series Analysis, 594 pp., Cambridge Univ. Press, Cambridge, U.K.

Rudeva, I., and S. Gulev (2007), Climatology of cyclone size characteristics and their changes during the cyclone life cycle, Mon. Weather Rev., 135, $2568-2587$.

Samelson, R., E. Skyllingstad, D. Chelton, S. Esbensen, L. O'Neill, and N. Thum (2006), On the coupling of wind stress and sea surface temperature, J. Clim., 19, 1557-1566.

Serreze, M. C., F. Carse, and R. G. Barry (1997), Icelandic low cyclone activity: Climatological features, linkages with the NAO, and relationships with recent changes in the Northern Hemisphere circulation, J. Clim., 10, 453-464. 
Simmonds, I. (2000), Size changes over the life of sea level cyclones in the NCEP reanalyses, Mon. Weather Rev., 128, 4118-4125.

Simmonds, I. (2003), Modes of atmospheric variabilitiy over the Southern Ocean, J. Geophys. Res., 108(C4), 8078, doi:10.1029/2000JC000542.

Simmonds, I., and D. A. Jones (1998), The mean structure and temporal variability of the semiannual oscillation in the southern extratropics, Int. J. Climatol., 18, 473-504.

Simmonds, I., and K. Keay (2000a), Variability of Southern Hemisphere extratropical cyclone behavior, 1958-97, J. Clim., 13, 550-561.

Simmonds, I., and K. Keay (2000b), Mean Southern Hemisphere extratropical cyclone behavior in the 40-year NCEP-NCAR reanalysis, J. Clim., $13,873-885$.

Simmonds, I., and R. J. Murray (1999), Southern extratropical cyclone behavior in ECMWF analyses during the FROST special observing periods, Weather Forecasting, 13, 878-891.

Simmonds, I., R. J. Murray, and R. M. Leighton (1999), A refinement of cyclone tracking methods with data from FROST, Aust. Meteorol. Mag., 35-49, June special edition.

Simmonds, I., K. Keay, and E.-P. Lim (2003), Synoptic activity in the seas around Antarctica, Mon. Weather Rev., 131, 272-288.

Sinclair, M. R. (1995), A climatology of cyclogenesis for the Southern Hemisphere, Mon. Weather Rev., 123, 1601-1619.

Sinclair, M. R. (1997), Objective identification of cyclones and their circulation intensity, and climatology, Weather Forecasting, 12, 595-612.

Treut, H. L., and E. Kalnay (1990), Comparison of observed and simulated cyclone frequency distribution as determined by an objective method, Atmosfera, 3, 57-71.

Turner, J., and M. Row (1989), Mesoscale vortices in the British Antarctic territory, in Polar and Arctic Lows, edited by P. F. Twitchell, E. A. Rasmussen, and K. L. Davidson, pp. 347-356, A. A. Deepak, Hampton, Va.

Turner, J., and J. P. Thomas (1994), Summer-season mesoscale cyclones in the Bellingshausen-Weddell Sea region of the Antarctic and links with the synoptic-scale environment, Int. J. Climatol., 14, 871-894.

Turner, J., G. Marshall, and T. Lachlan-Cope (1998), Analysis of synopticscale low pressure systems within the Antarcic Peninsula sector of the circumpolar trough, Int. J. Climatol., 18, 253-280. van Loon, H., J. W. Kidson, and A. B. Mullan (1993), Decadal variation of the annual cycle in the Australian dataset, J. Clim., 6, 1227-1231.

Von Ahn, J. M., J. M. Sienkiewicz, and G. M. McFadden (2006a), The application of sea level pressure and vorticity fields derived from the University of Washington Planetary Boundary Layer model in the NOAA Ocean Prediction Center, paper presented at Oceans 2006, Inst. of Electr. and Electron. Eng., Boston, Mass.

Von Ahn, J. M., J. M. Sienkiewicz, and J. Patoux (2006b), A comparison of sea level pressure analyses derived from QuikSCAT winds to manual surface analyses produced in the NOAA Ocean Prediction Center, paper presented at 21st Conference on Weather Analysis and Forecasting, Am. Meteorol. Soc., Washington, D. C.

Walland, D., and I. Simmonds (1999), Baroclinicity, meridional temperature gradients, and the southern semiannual oscillation, J. Clim., 12, $3376-3382$.

White, W., and I. Simmonds (2006), Sea surface temperature-induced cyclogenesis in the Antarctic circumpolar wave, J. Geophys. Res., 111, C08011, doi:10.1029/2004JC002395.

Wikle, C. K., R. F. Milliff, and W. G. Large (1999), Surface wind variability on spatial scales from 1 to $1000 \mathrm{~km}$ observed during TOGA COARE, J. Atmos. Sci., 56, 2222-2231.

Yuan, X., D. J. Martinson, and W. T. Liu (1999), Effect of air-sea interaction on winter 1996 Southern Ocean subpolar storm distribution, J. Geophys. Res., 104(D2), 1991-2007.

Yuan, X., J. Patoux, and C. Li (2009), Satellite-based midlatitude cyclone statistics over the southern ocean: 2. Tracks and surface fluxes, J. Geophys. Res., 114, D04106, doi:10.1029/2008JD010874.

Zierden, D. F., M. A. Bourassa, and J. J. O’Brien (2000), Cyclone surface pressure fields and frontogenesis from NASA scatterometer (NSCAT) winds, J. Geophys. Res., 105(C10), 23,967-23,981.

C. Li and X. Yuan, Lamont-Doherty Earth Observatory, Columbia University, 61 Route 9W, P.O. Box 1000, Palisades, NY 10964, USA. (xyuan@ldeo.columbia.edu)

J. Patoux, Department of Atmospheric Sciences, University of Washington, 408 ATG Building, Seattle, WA 98195-1640, USA. (jerome@atmos.washington.edu) 